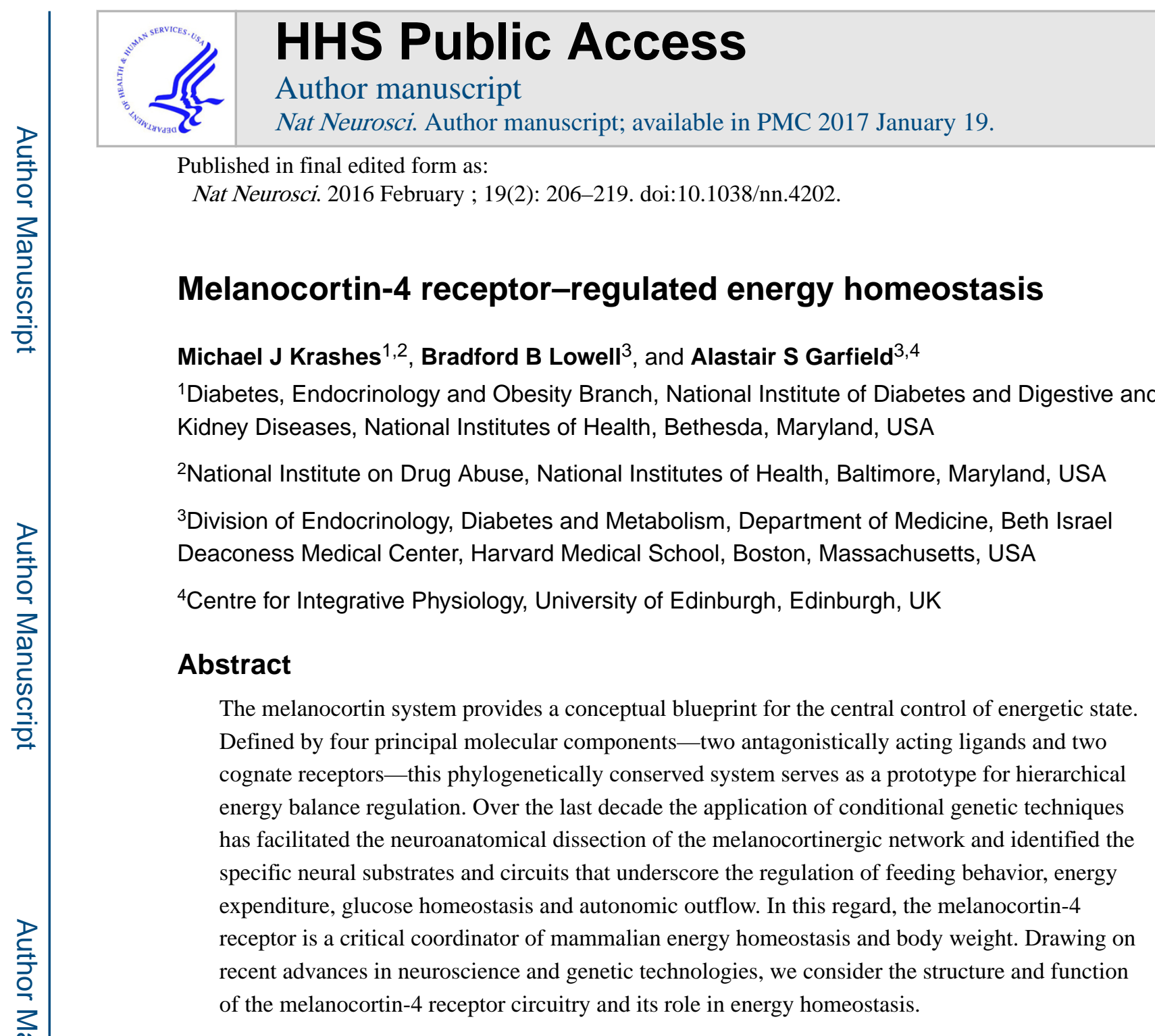

In mammals, homeostatic maintenance of energetic state is regulated by a sensory feedback system that attempts to preserve stability through the concerted modulation of both energy intake (as caloric consumption) and energy expenditure (as basal metabolism, adaptive thermogenesis and physical exertion). Ultimately, unbalancing of this equation is reflected by alterations in body weight, with a positive (intake > expenditure) or negative (intake < expenditure) energy balance engendering weight gain or loss, respectively. Although acute fluctuations in the relative levels of energy intake and expenditure are tolerated and redressed, chronic destabilization can have severe implications for health ${ }^{1}$ and longevity ${ }^{2}$. Furthermore, energy balance regulation biases toward defense against the lower, rather than upper, limits of adiposity. Since survival (rather than viability) is the evolutionary imperative, corpulence represents a 'fitter' state than does excessive leanness, which is associated with reduced reproductive function and, potentially, death. Teleologically, it is vital that detection of and response to periods of negative energy balance be safeguarded by

Reprints and permissions information is available online at http://www.nature.com/reprints/index.html.

Correspondence should be addressed to A.S.G. (agarfiel@staffmail.ed.ac.uk) or M.J.K. (michael.krashes@nih.gov).

COMPETING FINANCIAL INTERESTS

The authors declare no competing financial interests. 
a hardwired system that prevents starvation to guarantee survival. Unfortunately, the requisite rigidity of this system, while under strong selective pressure in a world of feast and famine, can be maladaptive in the modern age of caloric abundance, facilitating a chronic positive energy balance and consequent obesity.

Ultimately, this need-detection and response enactment is coordinated by the CNS in reaction to information from the periphery ${ }^{3}$. Episodic signals, associated with phasic oscillations in short-term energetic state (for example, before, during and after a meal), mediate the acute consummatory indices of hunger and satiety and adaptive thermoregulatory and metabolic aspects of energy expenditure, while chronic energetic state is reflected in tonic signaling from hormones positively correlated with adiposity ${ }^{3,4}$. Thus, long-term energetic indicators define a homeostatic tone to which the episodic modulation of acute energy balance is set. Overall energetic state, and hence body weight, is determined by the integration of these afferent signals at discrete sensory nodes within the brain. Located primarily in the hypothalamus and brainstem, such populations represent interoceptive entry points into hierarchical networks that collectively provide an awareness of energetic state and modulate feeding behavior, energy expenditure and metabolism accordingly ${ }^{3}$.

Deconvolving the circuitry that underlies this control has been a process driven principally by technological advance. The lesion studies of the mid-twentieth century defined the gross neuroanatomical architecture of energy balance networks, while the subsequent genetic era offered insight into the cellular populations and molecular substrates that define overall system functionality. Current understanding of the central melanocortin system epitomizes this evolution and provides a conceptual blueprint for the hardwired control of energetic state. Here we consider the present view of melanocortinergic energy homeostasis with a particular focus on second-order neuronal populations defined by their expression of the melanocortin-4 receptor (MC4R).

\section{The central melanocortin system}

Central melanocortinergic control of energy balance is predicated on an ability to distinguish current and acceptable energetic values, and subsequent rectification of any discrepancy through appropriate physiological and behavioral responses. This sensory function is provided by two counteracting populations of interoceptive neurons in the arcuate nucleus of the hypothalamus (ARC) ${ }^{4,5}$. ARC neurons expressing agouti-related peptide (AgRP) and coexpressing neuropeptide Y (NPY) and GABA represent the anabolic arm of the melanocortin pathway, robustly stimulated by caloric insufficiency 6,7 and necessary for driving energy intake, conserving energy expenditure and promoting weight gain ${ }^{8-10}$. By contrast, the catabolic interests of the system are defended by ARC neurons expressing proopiomelanocortin (POMC), which, in response to caloric sufficiency, promote a cessation of feeding, increased energy expenditure and weight loss $9,11,12$. The sensory capacity of $\mathrm{ARC}^{\mathrm{AgRP}}$ and $\mathrm{ARC}^{\mathrm{POMC}}$ neurons is contingent on their sensitivity to afferent inputs, both neuroendocrine and neural, that communicate acute and long-term energetic state (for review, see refs. 3,4). In rodents with ad libitum access to food, these signals oscillate in accordance with diurnal rhythm, such that the negative energy state fomented over the course of an animal's inactive period (light cycle) is redressed through food consumption 
during the active period (dark cycle). This flux in energy state is reflected in the in vivo electrical activity of genetically identified $\mathrm{ARC} \mathrm{AgRP}^{\mathrm{Ag}}$ and $\mathrm{ARC}^{\mathrm{POMC}}$ neurons, which exhibit a respective increase and decrease in action potential firing with mounting caloric deficiency ${ }^{13}$. Thus, consistent with their metabolic functions, the activity of $\mathrm{ARC}^{\mathrm{AgRP}}$ and $\mathrm{ARC}^{\mathrm{POMC}}$ neurons conveys a real-time awareness of energetic need, which in turn predicts neurotransmitter release and apposite physiological output.

Functionally, both AgRP and the bioactive products of POMC processing, $a-, \beta$ - and $\gamma$ melanocyte stimulating hormone (MSH), act as neuropeptides that engage cognate receptors on second-order post-synaptic targets ${ }^{4,5}$. Of five G-protein-coupled melanocortin receptors in the mammalian genome ${ }^{14}$, only the melanocortin-3 receptor and MC4R are represented in the CNS. A definitive role for the melanocortin-3 receptor in energy balance remains to be fully clarified and will not be discussed here (for review, see ref. 15). The MC4R is activated principally by a-MSH, leading to neuronal depolarization and action potential firing, while $\mathrm{AgRP}$ acts as an antagonist or biased agonist promoting neuronal hyperpolarization (see below). Central administration of MC4R agonists promotes satiety, energy expenditure and weight loss. MC4R antagonists increase food intake, energy conservation and weight gain $^{4,5}$. Thus, the diametric functionality of $\mathrm{ARC}^{\mathrm{AgRP}}$ and $\mathrm{ARC}{ }^{\mathrm{POMC}}$ neurons acting at downstream MC4R neurons underscores a bimodal system highly sensitive to fluctuations in energetic state.

Concordant with the catabolic function of a-MSH, genetic Pomc and $M c 4 r$ nullizygosity in mice ${ }^{16-18}$, and the inactivating $P O M C$ and $M C 4 R$ mutations in humans ${ }^{19-21}$ result in earlyonset obesity defined by hyperphagia and reduced energy expenditure. Genetic ablation of the mouse Agrp locus does not engender the expected hypophagic and lean phenotype ${ }^{22}$, most likely because of developmental redundancy. However, postnatal cytotoxic ablation of $\mathrm{ARC}^{\mathrm{AgRP}}$ neurons does result in hypophagia and leanness ${ }^{23-25}$, while postnatal ARC ${ }^{\mathrm{POMC}}$ neuron ablation promotes hyperphagia and obesity ${ }^{25}$. Together, these studies cogently demonstrate that the melanocortin ligands are critical to mammalian energy balance.

Modern neuroscience technologies now enable the real-time manipulation of genetically defined neuronal populations, without the confounding effects of developmental compensation or pharmacological non-specificity ${ }^{26}$. Chemogenetic ${ }^{10,27}$ and optogenetic ${ }^{8,28}$ activation of $\mathrm{ARC}^{\mathrm{AgRP}}$ neurons in calorically replete mice rapidly (within minutes) promotes voracious food seeking and consumption and an attenuation of energy utilization, which under chronic conditions drives weight accrual ${ }^{10}$. Conversely, chemogenetic silencing of ARC ${ }^{\mathrm{AgRP}}$ neurons engenders hypophagia in calorically deplete mice homeostatically motivated to eat ${ }^{10,27}$. Thus, $A R C^{A g R P}$ neurons are sufficient to drive an energy-saving motor program and are necessary for the enactment of deficiency-related feeding behaviors, including associated risk assessment and food seeking 29 .

The orexigenic function of inhibitory ARC ${ }^{\mathrm{AgRP}}$ neurons is served by the silencing of second-order satiety neurons. Although ARC ${ }^{\mathrm{AgRP}}$ neurons inhibit $\mathrm{ARC}^{\mathrm{POMC}}$ neurons ${ }^{9,30}$, this is not a mechanism by which they promote acute feeding ${ }^{9}$. Thus, the functional antagonism of these first-order populations is defined by their convergence at common second-order targets. In accordance, neuroanatomical tracing of $\mathrm{ARC}^{\mathrm{AgRP}}$ and $\mathrm{ARC}^{\mathrm{POMC}}$ 
efferents reveals highly comparable projection profiles ${ }^{31,32}$. Circuit-level use of optogenetics to experimentally isolate discrete $\mathrm{ARC}{ }^{\mathrm{AgRP}}$ projections demonstrates that these neurons drive feeding through their (noncollateralized) projections to the anterior bed nucleus of the stria terminalis, lateral hypothalamus and paraventricular nucleus of hypothalamus $(\mathrm{PVH})$, and to a lesser extent the paraventricular nucleus of the thalamus ${ }^{28}$. Pertinently, MC4R expression is closely correlated with these projections to the anterior bed nucleus of the stria terminalis, $\mathrm{PVH}$ and lateral hypothalamus ${ }^{33-35}$.

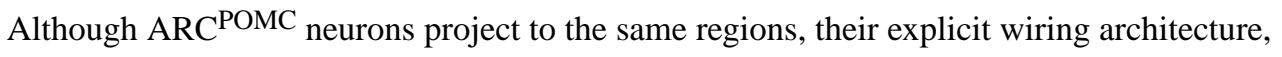
including which circuit-specific efferents are sufficient to promote satiety, is as yet unknown. Furthermore, the rapid temporal dynamics of ARC ${ }^{\mathrm{AgRP}}$ neuron-driven feeding contrasted with the far slower effects of ARC ${ }^{\mathrm{POMC}}$ neuron-driven satiety. Both chemogenetic ${ }^{11}$ and optogenetic ${ }^{8}$ stimulation of $\mathrm{ARC}^{\mathrm{POMC}}$ soma produces a late-onset hypophagic response, evident only after many hours of stimulation, and body weight loss. Similarly, chemogenetic silencing of these neurons augments long-term food intake but has no acute hyperphagic effect ${ }^{9}$. The explanation for the apparent temporal variance in $\mathrm{ARC}^{\mathrm{AgRP}}$ and $\mathrm{ARC}^{\mathrm{POMC}}$ neuron-regulated appetite is unclear but is likely attributable to their respective neurotransmitter complement and synaptic organization.

The acute consummatory effect of $\mathrm{ARC}{ }^{\mathrm{AgRP}}$ neurons is contingent on the release of GABA and/or NPY ${ }^{9,36}$. The concerted genetic inactivation of these two ARC ${ }^{\text {AgRP }}$ neuron systems (through $\mathrm{ARC}^{\mathrm{AgRP}}$ neuron deletion of $v$ Gat (Slc32aI) and global Npy nullizygosity) abolishes chemogenetic $\mathrm{ARC}^{\mathrm{AgRP}}$ neuron-driven feeding ${ }^{36}$, although in isolation neither mutation is functionally sufficient, suggesting that in a constitutive genetic context these two axes exhibit operative redundancy. Indeed, in $\mathrm{Npy}^{-/-}$mice $\mathrm{ARC}{ }^{\mathrm{AgRP}} \rightarrow \mathrm{PVH}$ GABAergic synaptic strength is potentiated, indicating some level of compensatory developmental rewiring 9 . In a developed neural system, however, pharmacological blockade of GABA or NPY signaling specifically in the PVH (at GABA $A_{A}$ receptors and $\mathrm{Y} 1$ receptors, respectively) independently abolishes optogenetic $\mathrm{ARC}^{\mathrm{AgRP}} \rightarrow \mathrm{PVH}$-driven feeding ${ }^{9}$, implying that both systems are required, and potentially cooperate ${ }^{37}$, to inhibit satiety-promoting PVH neurons. Unlike the rapid or exigenic effect of centrally infused NPY, AgRP administration is effective only after a number of hours ${ }^{38}$. In accordance, AgRP, acting at downstream melanocortin receptors, is dispensable for rapid chemo- and optogenetically induced feeding but is required to drive late-onset, longer term consumption ${ }^{8,36}$. Similarly, the slow-to-build anorectic effect of $\mathrm{ARC}^{\mathrm{POMC}}$ neurons is contingent on melanocortin receptor availability ${ }^{8}$. Thus, the rapid feeding induced by $\mathrm{ARC}^{\mathrm{AgRP}}$ neurons is defined by their release of fastacting neuroactive substances, while AgRP and a-MSH signaling at downstream MC4Rs defines a slower behavioral output.

The absence of a fast-acting neurotransmitter or neuropeptide potentially explains the lack of an acute satiety effect from $\mathrm{ARC}^{\mathrm{POMC}}$ neuron activation. However, several histological studies have identified GABAergic and glutamatergic subsets of $\mathrm{ARC}^{\mathrm{POMC}}$ neurons. These studies indicate that approximately $40 \%$ of $\mathrm{ARC}^{\mathrm{POMC}}$ somata are GABAergic, as defined by their expression of the GABA synthesis genes Gad65 and Gad67(refs. 39-41), although they do not express the vesicular GABA transporter (vGAT) ${ }^{40,42}$, suggesting that if these cells do release GABA an alternative transporter might be required for vesicular packaging. 
There is also evidence of a distinct glutamatergic $\mathrm{ARC}^{\mathrm{POMC}}$ subpopulation, though its reported relative proportion varies from $10 \%$ (refs. 40,42) to 50\% (ref. 39) depending on the labeling technique employed. At present, the functional significance of these subpopulations remains uncertain and may be defined by both circuit and physiological specificity that has not yet been investigated. As an example, stoichiometric analysis of $\mathrm{ARC}^{\mathrm{POMC}} \rightarrow \mathrm{PVH}$ synapses revealed approximately $50 \%$ to be glutamatergic but only $10 \%$ GABAergic $^{43}$ (although the use of vGAT as a marker of GABAergic terminals may underestimate the number of GABA-releasing synapses; see above). Ultrastructural modeling of melanocortinergic projections to the PVH demonstrated that, while $\mathrm{ARC}^{\mathrm{AgRP}}$ neurons form symmetric and predominantly axosomatic synapses at $\mathrm{PVH}$ neurons, $\mathrm{ARC} \mathrm{POMC}^{\mathrm{P}} \rightarrow \mathrm{PVH}$ neurons exhibit relatively weak and distal axo- dendritic connections ${ }^{43}$. Consistent with this, channelrhodopsin-assisted circuit mapping ${ }^{44}$, which serves as the gold standard for the identification of functional fast neurochemical synapses, identified robust monosynaptic GABAergic connectivity from $\mathrm{ARC}^{\mathrm{AgRP}}$ to approximately $50 \%$ of $\mathrm{PVH}$ neurons, while $\mathrm{ARC}^{\mathrm{POMC}}$ derived postsynaptic currents were limited to only $5 \%$ of PVH neurons (3\% excitatory and $2 \%$ inhibitory $)^{43}$. Thus, in contrast to $\mathrm{ARC}^{\mathrm{AgRP}}$ neurons, which demonstrate relative homogeneity, a cofunctional and consistent peptidergic and GABAergic nature and robust synaptic organization (at least in the $\mathrm{PVH}$ ), $\mathrm{ARC}^{\mathrm{POMC}}$ neurons exhibit neurochemical heterogeneity, a paucity of functional fast neurochemical connections and weak synaptic inputs (at least in the $\mathrm{PVH}$ ). While these observations likely explain the slow-to-build effect of $\mathrm{ARC}^{\mathrm{POMC}}$-driven satiety, it may also suggest the involvement of a more complex neural mechanism underlying melanocortinergically regulated satiety. For instance, it is possible that a-MSH release from $\mathrm{ARC}^{\mathrm{POMC}}$ neurons promotes synaptic restructuring and the modulation of fast transmitter inputs, such as has been observed in other melanocortinergic projections ${ }^{45,46}$. Furthermore, while $\mathrm{ARC}^{\mathrm{POMC}}$-neuron fast neurotransmitter synapses may not be required for the acute regulation of appetite, it remains to be investigated whether they play a more substantive role in other aspects of melanocortinergic physiology, such as autonomic outflow or glucose homeostasis.

\section{The melanocortin-4 receptor}

\section{Mouse models of MC4R function}

Concordant with its neuroanatomical distribution ${ }^{33-35}$ and myriad pharmacological observations $^{4,15}$, ablation of the mouse $M c 4 r$ locus produces a profound dysregulation of energy homeostasis, leading to overt early-onset obesity ${ }^{16}$ (Table 1). Mc4r insufficiency promotes hyperphagia, reduced energy utilization, increased fat mass, perturbed glucose homeostasis and sympatho-supression ${ }^{16,47,48}$. The ad libitum hyperphagia engendered by $M c 4 r$ nullizygosity is defined by exaggerated dark-cycle consumption ${ }^{49}$ and correlated with an increased motivation to attain food, suggesting enhanced goal-directed behavior ${ }^{50}$. The fidelity of the diurnal eating pattern and the normal response of $\mathrm{Mc} \mathrm{r}^{-1-}$ mice to periods of calorie restriction ${ }^{47}$ imply that sensory processing of hunger cues, likely at ARC ${ }^{\text {AgRP }}$ neurons, remains intact in these mutants. Thus, consistent with later studies ${ }^{8,36}$, the acute drive to consume food in response to energetic depletion is independent of AgRP $\rightarrow \mathrm{MC} 4 \mathrm{R}$ signaling and is maintained in these mutants presumably as a result of the continued efficacy of ARC ${ }^{\mathrm{AgRP}}$ neuron NPY and GABA release. Protracted within-meal consumption is 
therefore likely to be explained by a failure of a-MSH induced satiety. In agreement, Pomc deficiency ${ }^{17,18}$ recapitulates most of the $\mathrm{Mc} \mathrm{r}^{-/-}$phenotype, including obesity, increased axial length and hypersensitivity to an obesogenic diet. Furthermore, human null mutations in either $M C 4 R^{19,20,51,52}$ or $P O M C^{21}$ lead to syndromic obesity that mirrors the respective mouse phenotype, cogently highlighting the phylogenetic conservation of this system.

While these global knockout lines demonstrate the importance of MC4R signaling to the control of energy balance, the specific neural populations accountable for the pleiotropic

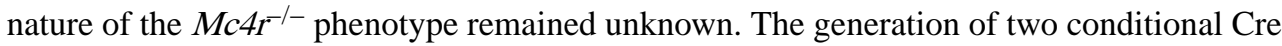
recombinase-dependent $M c 4 r$ alleles was fundamental to the neuroanatomical dissection of MC4R function (Fig. 1 and Table 2). To assess functional sufficiency, a reactivatable $M c 4 r$ null allele was generated through the insertion of a Cre-dependent lox $P$-flanked transcriptional blocking sequence $\left(M c 4 I^{\text {loxTB/loxTB }}\right)^{53}$. Necessity was addressed with a complementary $M c 4 I^{\text {JoxPllox } P}$ inactivation allele ${ }^{54}$ (Fig. 1). In the presence of an appropriate Cre-expressing driver line, these alleles are reactivated or deleted, respectively, in a molecularly defined fashion (Tables 1 and 2). As expected, mice homozygous for the disrupted $M c 4 r^{\text {loxTB/loxTB }}$ allele phenocopy the global $M c 4 r^{-/-}$knockout $^{53}$. However, neuron-specific reactivation of the $M c 4 r^{\text {JoxTB/IoxTB }}$ allele completely ameliorates obesity, indicating a central site of action for energy balance regulating MC4Rs ${ }^{53}$. More specifically, this effect is attributable to the expression of MC4Rs on glutamatergic neurons, since reexpression of the Mc4l ${ }^{\text {loxTB/loxTB }}$ allele using a vGlut2-(Slc17a6)-ires-Cre line completely rescues body weight, adiposity, hyperphagia, energy expenditure, axial length and glucose homeostasis ${ }^{54}$. Correspondingly, while $M c 4 r^{\text {loxPlloxP }}$ mice are phenotypically normal, deletion of this allele from vGLUT2 neurons promotes a metabolic phenotype comparable to global Mc4r nullizygosity ${ }^{54}$. Re-expression or deletion of MC4Rs on GABAergic neurons has no discernible phenotypic effect ${ }^{54}$. Thus, whatever the identity of the MC4R neurons responsible for the pleiotropy of the $\mathrm{Mc} \mathrm{r}^{-/-}$mouse, they are most likely glutamatergic.

Although CNS MC4Rs have been the predominant focus for energy balance research, recent work has highlighted the contribution of MC4Rs in enteroendocrine L-cells of the intestine. These have been demonstrated to (i) regulate luminal electrolyte secretion, to potentially reduce gastric motility and enhance between-meal satiety, and (ii) promote release of the episodic satiety factors glucagon-like peptide-1 (GLP1) and peptide YY (PYY), potentially enhancing centrally mediated MC4R satiety ${ }^{55}$. The functional significance of these observations remains unknown, but is noteworthy given the correlation between MC4R signaling and the weight-loss efficacy of bariatric surgeries ${ }^{56,57}$.

\section{Energy intake}

Pharmacological studies have been critical in directing genetic dissection of the melanocortin system. While MC4Rs in numerous sites are neuroanatomically positioned to promote satiety, at least when pharmacology probed ${ }^{38,58,59}$, it is the PVH that has garnered the most attention. Highlighted by the importance of the PVH to energy homeostasis ${ }^{60}$ and robust MC4R expression ${ }^{35,53}$, microinjections of a-MSH or AgRP into this region engender satiety and hunger, respectively, at levels beyond that seen at any other site ${ }^{61}$, suggesting that 
$\mathrm{PVH}^{\mathrm{MC} 4 \mathrm{Rs}}$ represents a point of functional convergence for counteractive $\mathrm{ARC}^{\mathrm{AgRP}}$ and $\mathrm{ARC}^{\mathrm{POMC}}$ neurons.

The ontology of the PVH is defined by the transcription factor Single-minded 1 (Sim1). Developmental haploinsufficient Sim $^{+/-}$(refs. 62,63) and postnatal Sim $^{-1-}$ (ref. 64) mutant mice exhibit profound obesity, hyperphagia and increased axial length, in a manner reminiscent of the global $\mathrm{Mc}_{\mathrm{r}} \mathrm{F}^{-1-}$ mutant, but retain normal energy expenditure. Notably, $\mathrm{Sim}^{+/-}$mice exhibit resistance to the hypophagic, but not exergonic, effects of intra-PVH

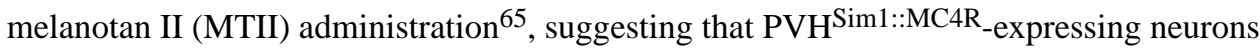
are a critical component of MC4R-regulated appetite but not energy expenditure. To address this directly, a BAC (bacterial artificial chromosome) transgenic Sim1-Cre line was used to drive molecularly defined recombination of conditional $M c 4 r$ alleles. Selective restoration of MC4Rs to Sim1-expressing neurons (Sim1-Cre::Mc4r IoxTB/loxTB ) on an otherwise $M c 4 r$ null background was found to reduce body weight by $\sim 60 \%$, owing primarily to decreased adiposity and rescued axial length ${ }^{53}$. Remarkably, this reduction in body weight is defined by a complete normalization of feeding behavior, but no improvement in energy expenditure ${ }^{53}$. Sim1-Cre::Mc4I ${ }^{\text {loxTB/loxTB }}$ mice also exhibit restored sensitivity to the hypophagic, but not hypermetabolic, effects of MTII ${ }^{53}$. The deletion of MC4R-expressing Sim1-positive neurons ( $\mathrm{Sim} 1^{\mathrm{MC} 4 \mathrm{Rs}}$; Sim1-Cre::Mc4I ${ }^{\text {loxPlloxP }}$ ) results in reciprocal hyperphagia and obesity ${ }^{54}$. However, these mice were lighter than vGlut2-iresCre::Mc4r $I^{\text {loxPl/oxP }}$ mice, indicating that other glutamatergic MC4R populations, regulating energy expenditure, contribute to body weight. Therefore, Sim1 ${ }^{\mathrm{MC} 4 \mathrm{Rs}}$ neurons are both sufficient and necessary for the physiological control of homeostatic feeding and body weight, but not energy expenditure, indicating a functional divergence in the energy-balance melanocortinergic circuitry.

Although these effects were attributed to MC4R expression in $\mathrm{PVH}^{\mathrm{SIM} 1}$ neurons, allelic recombination in other brain areas demarked by Sim1-Cre expression ${ }^{53}$ or unobserved developmental compensatory mechanisms could contribute to the observed phenotypes. To circumvent these obstacles, postnatal specific recombination was achieved through the stereotaxic injection of a Cre-expressing adeno-associated virus (AAV-Cre) into distinct neuroanatomical structures of adult $M c 4 r^{\text {IoxTB/loxTB }}$ and $M c 4 r^{\text {IoxPI/loxP }}$ mice. Consistent with the Sim1-Cre::Mc4I IoxPlloxP phenotype, AAV-Cre deletion of $\mathrm{PVH}^{\mathrm{MC} 4 \mathrm{Rs}}$ results in hyperphagia, increased adiposity and obesity ${ }^{54}$, while PVH-specific $M c 4 r$ re-expression in $M c 4 I^{\text {IOXTB/ IoxTB }}$ mice reciprocally reduces the obesity and hyperphagia associated with $M c 4 r$ nullizygosity ${ }^{53,54}$. In contrast, rescued $M c 4 r$ expression in the medial amygdala ${ }^{54}$, the lateral parabrachial nucleus (LPBN) ${ }^{54}$, the nucleus of the solitary tract (NTS) and dorsomedial nucleus of the vagus (DMV) $)^{54}$, or the lateral hypothalamus ${ }^{66}$ has no effect on feeding behavior. Thus, $\mathrm{PVH}^{\text {Sim1::MC4Rs }}$ are the main component of MC4R-regulated satiety.

To further refine the neurochemical subtype of energy-balance-regulating $\mathrm{PVH}^{\mathrm{MC} 4 \mathrm{R}}$ neurons, a battery of knock-in Cre-expressing mice, demarking specific subpopulations of PVH neurons, was used to determine the sufficiency of $M c 4 r$ reactivation in a neurochemically explicit manner. Re-expression of MC4Rs in neurons expressing corticotropin-releasing hormone (Crh-ires-Cre) and/or oxytocin (Oxt-ires-Cre), arginine 
vasopressin (Avp-ires-Cre) or prodynorphin (Pdyn-ires-Cre) does not reduce body weight ${ }^{54}$, suggesting that MC4Rs expressed on any one of these populations alone does not contribute to energy homeostasis. However, regardless of the uncertain neuropeptidergic identity of $\mathrm{PVH}^{\text {Sim1::MC4R }}$ neurons, it is likely that their body-weight-regulating function is primarily contingent on their release of glutamate, since re-expression of $M c 4 r$ and concomitant deletion of vGlut2 in Sim1 neurons nullifies the improvement in Sim1-Cre::Mc4I ${ }^{\text {loxTB/loxTB }}$ phenotype $^{67}$.

As yet, the only other population of MC4Rs to be genetically implicated in the regulation of feeding are those demarked by a dopamine-1 receptor (Drd1)-Cre line ${ }^{49}$. Drd1-

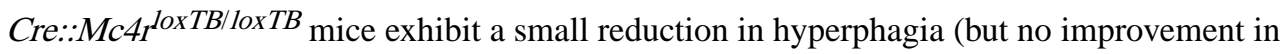
energy expenditure) that results in a $10 \%$ decrease in body weight ${ }^{49}$. While the specific population of Drd1 ${ }^{\mathrm{MC}} 4 \mathrm{R}$ expressing neurons responsible for this phenotype remains to be determined, it is possible that partial coexpression (and subsequent reactivation) ${ }^{68}$ in the PVH contributes to this mild improvement in energetic balance.

\section{Energy expenditure}

The incomplete rescue of body weight in Sim1-Cre::Mc4r $r^{\text {loxTB/loxTB }}$ mice, despite complete normalization of feeding behavior, is underscored by persistent hypometabolism comparable to that in $M c 4 r$-deficient mice ${ }^{53}$. Concordantly, Sim1-Cre:: $M c 4 r^{\text {IoxTB/loxTB }}$ animals are insensitive to the exergonic effects of MC4R agonism ${ }^{53}$, confirming that Sim1 ${ }^{\mathrm{MC} 4 \mathrm{Rs}}$ are not responsible for MC4R-regulated energy utilization. Genetic studies have since identified MC4Rs on cholinergic preganglionic sympathetic neurons of the intermediolateral nucleus of the spinal cord (IML) as the critical population ${ }^{69,70}$. These neurons, like their parasympathetic counterparts in the DMV, are defined by their expression of choline acetyltransferase (ChAT). Chat-ires-Cre-mediated recombination of the $M c 4 I^{\text {loxTB/loxTB }}$ allele therefore enables re-expression of MC4Rs on the two efferent arms of the autonomic nervous system (ANS). Chat-ires-Cre::Mc4I IoxTB/loxTB mice, while still obese, exhibit a $10 \%$ drop in body weight that is entirely facilitated by the reinstatement of normal energy expenditure, with no reduction in food intake ${ }^{69}$. To functionally distinguish the relative contribution of IML ${ }^{\text {MC4Rs }}$ and DMV ${ }^{\text {MC4Rs }}$, a subtractive genetic strategy used a Phox $2 b$ Cre line that labels preganglionic parasympathetic DMV neurons but not preganglionic IML neurons. Unlike Chat-ires-Cre::Mc4I IoxTB/loxTB mice, Phox $2 b-C r e:: M c 4 I^{\text {loxTB/loxTB }}$ mice do not exhibit improved energy expenditure, suggesting that it is IML ${ }^{\text {MC4Rs }}$ that define this function ${ }^{69}$. Similarly, deletion of MC4Rs from Chat-expressing, but not Phox $2 b$-expressing, neurons results in decreased oxygen consumption and in subsequent obesity, with no effect on food consumption ${ }^{70}$. Although ChAT ${ }^{\mathrm{MC} 4 \mathrm{Rs}}$ undoubtedly contribute to the hypometabolic state of $\mathrm{Mc} \mathrm{r}^{-/}$- mice they are seemingly not the totality of energy-expenditure MC4R neurons, since $\mathrm{Mc}_{\mathrm{r}} \mathrm{r}^{-/-}$mice still exhibit lower energy expenditure than Chat-iresCre::Mc4r ${ }^{\text {loxPlloxP }}$ mice $^{70}$. On the basis of pharmacological data, it is possible that MC4Rs expressed in the median pre-optic nucleus and/or DMH may contribute to some elements of melanocortin-regulated energy expenditure ${ }^{71}$.

The role of $\mathrm{ChAT}^{\mathrm{MC} 4 \mathrm{Rs}}$ neurons in energy expenditure is most readily observed in the adaptive response to environmental challenge, such as exposure to a high-calorie diet (HCD) 
or a cold environment. Wild-type mice presented with a HCD exhibit hyperthermia and increased energy expenditure that restrain body weight gain; $\mathrm{Mc}^{-\mathrm{r}^{-1-}}$ and Chat-iresCre::Mc4I ${ }^{\text {loxP/lox } P}$ mice, by contrast, fail to enact these adaptive responses ${ }^{47,70}$.

Mechanistically, this elevation in body temperature is mediated by brown adipose tissue (BAT), which is potently activated by the sympathetic nervous system (SNS) and a vital component of melanocortinergic adaptive thermogenesis ${ }^{47,72-74}$. SNS outflow to BAT promotes mitochondrial uncoupling, leading to proton leakage and the generation of heat. This process depends on mitochondrial uncoupling protein-1 (UCP1 $)^{75}$. Both $\mathrm{Mc}_{\mathrm{r}} \mathrm{r}^{-1-}$ and Chat-ires-Cre::Mc4I IoxP/loxP mice fail to upregulate UCP1 expression in response to a HCD, suggesting that compromised MC4R-mediated SNS outflow to BAT ${ }^{70}$ contributes to their sensitivity to an obesogenic diet. Although UCP1 expression can also be regulated by the hypothalamic-pituitary-thyroid axis, this system is not a functional target for the MC4R dietary response, since $\mathrm{Mc}_{4} \mathrm{r}^{-/-}$mice exhibit normal thyroid hormone levels and apposite thyroid responses to a $\mathrm{HCD}^{72}$. Acute cold exposure similarly engenders SNS-regulated BATmediated thermogenesis that is required for maintaining core body temperature. In this regard it would seem that MC4Rs do not contribute, since two separate studies found $M c 4 r^{-/-}$mice to exhibit normal basal body temperature in ambient conditions and apposite thermogenic responses to cold exposure ${ }^{47,48}$.

Autonomic outflow to white adipose tissue (WAT), the silo for excess caloric energy, is important in regulating lipid metabolism and composition ${ }^{76}$. Sympathetically mediated 'beiging' of BAT-like progenitors in WAT has been proposed as an adaptive response to environmental stressors, such as cold exposure and obesogenic diet ${ }^{77}$. This evoked development of UCP1-expressing beige cells elevates body temperature and energy expenditure. Central MC4R-expressing neurons in several sites are anatomically connected

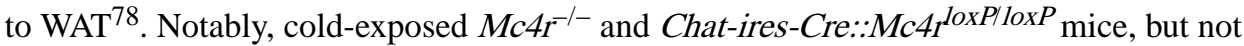
Phox $2 b-C r e:: M c 4 I^{\text {loxPlloxP }}$ mice, fail to show evidence of beiging ${ }^{70}$, suggesting that MC4Rregulated SNS outflow to WAT is required for the induction of this adaptive response. Whether a similar mechanism underlies diet-induced beiging remains to be determined. Real-time chemogenetic activation of $\mathrm{ARC}^{\mathrm{POMC}}$ neurons drives an SNS- dependent beiging effect $^{12}$, implicating an $\mathrm{ARC}^{\mathrm{POMC}} \rightarrow \mathrm{IML}^{\mathrm{MC} 4 \mathrm{R}}$ circuit in this process.

\section{Glucose homeostasis}

$M c 4 r$ deficiency in mice is associated with hyperglycemia and hyperinsulinemia that precede the onset of obesity but are exacerbated by fat accrual ${ }^{16,48,79}$. By contrast, human $M C 4 R$ deficiency results in euglycemic hyperinsulinemia during childhood but a normalization of insulin levels during adulthood, with no manifestation of diabetes $51,52,80$. Thus, it would seem that at least the initiating hyperinsulinemic state is conserved in the

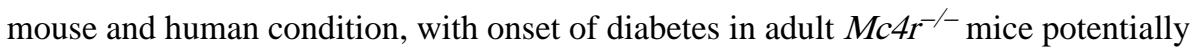
defined by subsequent body-weight-dependent insulin resistance. Furthermore, congenic

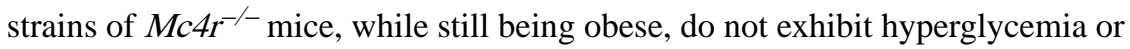
hyperinsulinemia ${ }^{81}$, suggesting that there is a role for strain-specific (body-weightindependent) genetic modifiers in the etiology of glycemic dysregulation. It is possible that such genetic nuances also explain the phenotypic differences between $M c 4 r$ and $M C 4 R$ nullizygous mice and humans. 
Centrally governed glycemia is regulated by the ANS. ChAT ${ }^{\mathrm{Mc} 4 \mathrm{r}}$ re-expression, including re-expression on preganglionic autonomic neurons, moderately improves hyperglycemia and hyperinsulinemia, as compared to that in $M c 4 I^{\text {loxTB/IoxTB }}$ controls ${ }^{69}$. Reciprocally, $M c 4 r$ deletion in Chat-ires-Cre::Mc4t $I^{\text {loxPlloxP }}$ mice promotes a diabetic hyperinsulinemic phenotype $^{70}$. To dissociate the contributions of the two arms of the ANS, the same measures were taken in Phox $2 b-C r e:: M c 4 r^{\text {loxTBlloxTB }}$ and Phox $2 b-C r e:: M c 4 r^{\text {loxPlloxP }}$ mice.

Phox $2 \mathrm{~b}^{\mathrm{Mc} 4 \mathrm{r}}$ re-expression results in normalized insulin levels but persistent hyperglycemia ${ }^{69}$; Phox $2 b-C r e:: M c 4 I^{\text {loxPl/oxP }}$ mice are mildly hyperinsulinemic (although not to the extent of $\mathrm{Mc} \mathrm{r}^{-/-}$controls) but normoglycemic ${ }^{70}$. Together these results suggest that that preganglionic parasympathetic Phox $2 b^{\text {MC4Rs }}$ suppress PNS outflow to inhibit pancreatic insulin release, but that this does not influence overall glycemic state or insulin sensitivity, while preganglionic sympathetic $\mathrm{ChAT}^{\mathrm{MC} 4 \mathrm{Rs}}$ do not directly influence insulin release but do set general glycemic tone.

Given that PNS outflow stimulates insulin release, this implies that MC4Rs inhibit rather than activate DMV neurons. Indeed, MC4R agonists cause hyperpolarization at most $\mathrm{DMV}^{\mathrm{ChAT}}$ neurons ${ }^{82}$ (see below). Thus, global or DMV-specific $M c 4 r$ deficiency results in exaggerated PNS outflow to the pancreas and hyperinsulinemia. However, the role of $\mathrm{ChAT}^{\mathrm{MC} 4 \mathrm{Rs}}$ is seemingly more complex. Specifically, given the stimulatory effect ${ }^{82}$ of $\mathrm{IML}^{\mathrm{MC} 4 \mathrm{Rs}}$, and given that SNS outflow promotes glucose production and excursion, it is surprising that the sympatho-suppressed state of $\mathrm{Mc} \mathrm{r}^{-/-}$and Chat-ires-Cre::Mc4r IoxP/loxP mice actually drives a sympatho- excitatory phenotype (increased glucose excursion and reduced glucose disposal $)^{70}$. It is possible that it is in fact body composition that is the main defining factor in this phenotype, such that the mildly reduced body weight of Chat-iresCre::Mc4I IoxTB/loxTB mice ${ }^{69}$ and the obesity of Chat-ires-Cre::Mc4I $I^{\text {loxPlloxP }}$ mice ${ }^{70}$ explains their improvement and deterioration in glycemic state, respectively. This notion is supported by the normoglycemia exhibited by $M c 4 r^{-/-}$mice pair-fed to wild type levels ${ }^{48}$ and ad libitum fed Sim1-Cre::Mc4t IoxTB/loxTB mice ${ }^{53}$, which have reduced body weight. However, it is likely that the MC4R is involved in least some element of glycemic control, independently of its body weight effects, since AAV-Cre mediated Mc4r re-expression in the lateral hypothalamus mildly improves SNS-dependent glucose tolerance (but not basal glycemic state) in adult $M c 4 I^{\text {loxTB/loxTB }}$ mice, without altering body weight or composition 66 .

\section{Additional autonomic functions}

Central administration of a-MSH elevates blood pressure and heart rate in an SNS- and MC4R-dependent manner ${ }^{83,84}$. This corollary of wholesale MC4R activation has significantly hampered the development of MC4R-based weight-loss pharmacotherapies ${ }^{85}$. Consistent with an MC4R pressor effect, $\mathrm{Mc} \mathrm{I}^{-1-}$ mice exhibit paradoxical normotension and tachycardia, despite being obese, hyperinsulinemic and hyperleptinemic ${ }^{86}$. However, the re-establishment of autonomic tone in Chat-ires-Cre::Mc4r ${ }^{\text {loxTB/loxTB }}$ mice unmasks a hypertensive phenotype in accord with their obese state ${ }^{82}$, suggesting that direct MC4R engagement of preganglionic autonomic neurons underlies their regulation of cardiovascular function. In obese $M C 4 R$-deficient humans, most of whom are similarly normotensive and tachycardic ${ }^{80}$, there is evidence of both PNS and SNS involvement, consistent with $M C 4 R$ 
nullizygosity engendering both parasympatho-excitation and sympatho-suppression (for review, see ref. 87). The contribution of DMVMC4Rs to the $\mathrm{Mc} 4 \mathrm{r}^{-/-}$knockout cardiovascular phenotype remains unexplored. Despite the preautonomic role of the PVH and the mild pressor effect observed upon intra-PVH agonist infusion ${ }^{88-90}, \mathrm{Sim}^{\mathrm{MC} 4 \mathrm{R}}$ re-expression does not cause hypertension. However the non-obese nature of these animals may mean that, even if autonomic tone were partially rescued (which remains unknown), there is no initiating pathology to drive hypertension ${ }^{82}$. Dissociating the neural mechanisms underlying the MC4R pressor effect will be critical for the generation of energy-balance-regulating MC4R compounds devoid of cardiovascular side effects for the safe and effective treatment of obesity.

Further to its effects on WAT composition, MC4R-regulated ANS outflow modulates peripheral lipid metabolism to influence the deposition and circulation of fat. $M c 4 r$ - and $M C 4 R$-deficient mice ${ }^{91}$ and humans ${ }^{92}$ exhibit elevated respiratory quotients, indicative of a shift from fat utilization to fat storage. This perturbation in substrate utilization exacerbates adipose tissue expansion and weight gain beyond that defined simply by a net positive energy balance. In light of MC4R expression in preganglionic IML neurons ${ }^{69}$, as well as in preautonomic outflow neurons innervating $\mathrm{WAT}^{78}$, it is likely that these phenotypes are defined by generalized sympatho-suppression. Indeed, pharmacological blockade of central MC4R signaling engenders an increase in respiratory quotient, WAT lipid content and lipogenic gene expression in an SNS-dependent, but body-weight-independent, manner ${ }^{92}$. Furthermore, MC4R engagement of the parasympathetic nervous system regulates hepatic cholesterol uptake such that genetic or pharmacological inactivation of central murine ${ }^{93}$ (but not human ${ }^{80}$ ) MC4R signaling elevates circulating levels of cholesterol and high density lipoprotein:cholesterol complexes. Thus, MC4R-regulated autonomic tone influences nutrient handling and lipid metabolism independently of obesity to contribute to metabolic fitness.

\section{PVH MC4R neural circuitry}

Conditional genetic manipulations have been fundamental to defining the neuroanatomical landscape of $M c 4 r$-regulated physiology. However, the neural interactions underlying functional outflow can only be resolved through the application of circuit-level cellular technologies. Unlike pharmacological and germline genetic approaches, such tools do not directly address the contribution of an individual molecular component, but rather provide insight into the significance of an explicit population (as defined by a Cre driver mouse line; Fig. 1) expressing that component.

Consistent with role of $\mathrm{PVH}^{\mathrm{MC} 4 \mathrm{Rs}}$ in the regulation of energy intake $\mathrm{e}^{53,54}$ chemogenetic activation of Cre-expressing $\mathrm{PVH}^{\mathrm{MC} 4 \mathrm{R}}$ neurons promotes satiety during times of physiological hunger, indicating that they are neuroanatomically positioned to suppress homeostatic feeding ${ }^{35}$. Activation of $\mathrm{PVH}^{\mathrm{MC} 4 \mathrm{R}}$ neurons has no effect on energy expenditure, validating prior genetic observations ${ }^{53}$. Loss-of-function studies further demonstrate that these neurons are necessary for the maintenance of satiety, such that their inactivation during times of caloric sufficiency results in increased goal-directed light-cycle food consumption ${ }^{35}$. Given the functional reciprocity of the melanocortin ligands, the 
bidirectionality of $\mathrm{PVH}^{\mathrm{MC} 4 \mathrm{R}}$-regulated appetite supports their position as a point of functional convergence for inhibitory feeding-promoting $\mathrm{ARC}^{\mathrm{AgRP}}$ neurons and excitatory satiety-promoting $\mathrm{ARC}^{\mathrm{POMC}}$ neurons. Indeed, channelrhodopsin-assisted circuit mapping demonstrates that the vast majority of $\mathrm{PVH}^{\mathrm{MC} 4 \mathrm{R}}$ neurons receive GABAergic input from $\mathrm{ARC}^{\mathrm{AgRP}}$ neurons and that this interaction is necessary for $\mathrm{ARC} \mathrm{AgRP}^{\mathrm{AgV}} \mathrm{PVH}$-driven feeding. However, the rapid feeding effects engendered by ARC ${ }^{\mathrm{AgRP}} \rightarrow \mathrm{PVH}$ photostimulation or artificial $\mathrm{PVH}^{\mathrm{MC}} 4 \mathrm{R}$ manipulations do not necessarily speak to the explicit function of MC4Rs. In this regard, beyond their expression of a cognate receptor and sensitivity to selective pharmacological agonists ${ }^{35}$, the functional role of endogenous $\mathrm{AgRP}$ or a-MSH at $\mathrm{PVH}^{\mathrm{MC} 4 \mathrm{R}}$ neurons remains to be determined. It will be important to further refine the position of $\mathrm{PVH}^{\mathrm{MC} 4 \mathrm{R}}$ neurons downstream of $\mathrm{ARC}^{\mathrm{POMC}}$ neurons, since this is the circuit that ultimately defines satiety.

Sites of functional outflow for $\mathrm{PVH}^{\mathrm{MC} 4 \mathrm{R}}$ neurons were identified through efferent projection mapping ${ }^{35}$. Since glutamate release is critical to the function of $\mathrm{PVH}^{\mathrm{MC} 4 \mathrm{R}}$ neurons ${ }^{54,67}$, putative postsynaptic cells in efferent sites were assayed for excitatory monosynaptic connections arising from presynaptic $\mathrm{PVH}^{\mathrm{MC} 4 \mathrm{R}}$ neurons. Despite a broad descending projection profile, glutamatergic connections were identified only in the LPBN and DMV, implicating these site as prospective third-order nodes involved in feeding regulation ${ }^{35}$. Connected LPBN neurons are located specifically in the central compartment (cLPBN). In vivo optogenetic stimulation of $\mathrm{PVH}^{\mathrm{MC} 4 \mathrm{R}} \rightarrow \mathrm{cLPBN}$ terminals, but not those in DMV or ventrolateral periaqueductal gray, promotes satiety, confirming this structure as site of functional outflow for melanocortin-regulated appetite. In this regard, the role of the LPBN as an interoceptive rely ${ }^{94}$ befits its role in appetite regulation. LPBN lesions induce hyperphagia and obesity ${ }^{95}$, and hyporesponsivity to anorectic neuroendocrine factors ${ }^{96}$. Input from ascending sensory afferents (both vagal, via NTS, or spinal) ${ }^{94}$, in addition to a direct chemosensing capacity ${ }^{97,98}$, influences LPBN neuron activity in a viscerotopic fashion. Thus, it is possible that a neurochemically defined satiety population or populations integrates both ingestion-related visceral stimuli and hypothalamically derived homeostatic information to jointly determine behavioral and physiological responses to food consumption. The explicit identity of the cLPBN satiety population engaged by $\mathrm{PVH}^{\mathrm{MC}} 4 \mathrm{R}$ neurons remains unknown, but it is glutamatergic, as LPBN ${ }^{\mathrm{vGLUT2}}$ neurons are necessary for the real-time maintenance of satiety and are selectively engaged by $\mathrm{PVH}^{\mathrm{MC} 4 \mathrm{R}}$ neurons ${ }^{35,54}$. Furthermore, these satiety cLPBN neurons are distinct from appetitesuppressing calcitonin-gene related peptide (CGRP)- expressing neurons in the external LPBN (eLPBN). eLPBNCGRP neurons inhibit food consumption under conditions in which it is unfavorable to eat (such as sickness) ${ }^{99}$ and a carry negative valence when optogenetically activated ${ }^{100}$. That satiety-promoting $\mathrm{PVH}^{\mathrm{MC} 4 \mathrm{R}} \rightarrow \mathrm{cLPBN}$ neurons do not engage eLPBN ${ }^{C G R P}$ neurons demonstrates how specific neuroanatomical circuits subserve the context-specific regulation of food intake.

In its most simplistic biological form, appetite is a function of energy requirement. The physiological representation of this caloric need is recognized as hunger, the detection of which ensures the motivation to enact behaviors that lead to food consumption (Fig. 2a). Recent work has demonstrated that the motivation to engage in these behaviors is driven by the aversive nature of hunger, as represented by $\mathrm{ARC}^{\mathrm{AgRP}}$ neuron activation ${ }^{101}$, which 
promotes a negative physiological state that is alleviated upon caloric intake ${ }^{102}$. Thus, the consumption of food, and hence satiety, is reinforcing to ensure the motivation required to respond to periods of caloric deficiency. Supporting this, experimentally induced satiety through optogenetic stimulation of $\mathrm{PVH}^{\mathrm{MC} 4 \mathrm{R}} \rightarrow$ LPBN terminals ${ }^{35}$ (or chemogenetic silencing of ARC ${ }^{\mathrm{AgRP}}$ neurons ${ }^{101}$ ) encodes a positive valence that hungry mice preferentially seek out, essentially alleviating their hunger through self-stimulation of this neural circuit (Fig. 2b). Remarkably, the positive valance encoded by ARC ${ }^{\text {AgRP }}$ neuron silencing and $\mathrm{PVH}^{\mathrm{MC} 4 \mathrm{R}}$ neuron activation in hungry mice is energy-state dependent, such that in calorically sated mice the activation and silencing of these populations, respectively, no longer represents a preferential state (Fig. 2c) 35,101 .

In experimentally distilling the motivational basis of feeding behavior, these complementary studies demonstrate, consistent with early theories concerning need states and their homeostatic rectification ${ }^{103,104}$, that the motivation to enact the behaviors (food-seeking and consumption) that fulfill an unmet need (caloric insufficiency) is driven by the negative valence of the physiological state (hunger) and that reestablishment of homeostasis encodes a positive valence associated with relief from this state. It is tempting to speculate that the unpleasant feelings associated with hunger, combined with the relief, if not pleasure, that comes from subsequent food consumption, is one of the main reasons why dieting proves so difficult. Specifically, the motivational incentive to respond to periods of hunger (a state exaggerated by dieting) has evolved to be a robust and unerring survival drive, the disregard of which is difficult. Consequently, the therapeutic activation of a system that encodes both satiety and positive valence (such as $\mathrm{PVH}^{\mathrm{MC} 4 \mathrm{R}} \rightarrow \mathrm{LPBN}$ ) could conceivably serve as a potent adjunct to caloric restriction for the treatment of obesity.

\section{MC4R signal transduction}

The physiological functions of the MC4R are ultimately defined by the intracellular mechanisms that transduce ligand-receptor interactions into neuronal excitability. Although originally defined as a $\mathrm{Ga}_{\mathrm{s}}$-coupled receptor, recent investigation into the nature of the binding of a-MSH and AgRP to MC4Rs have revealed the diversity of signaling cascades engaged by their orthosteric binding ${ }^{105}$. Depending on cellular context, application of MC4R agonists promotes $\mathrm{G}_{\mathrm{s}}$-dependent cyclic AMP synthesis106, $\mathrm{G}_{\mathrm{q}}$-dependent phospholipase-C activity ${ }^{107}$ and G-protein-dependent MAPK signaling ${ }^{108-110}$. However, these studies relied on heterologous in vitro systems, and thus their extrapolation to in vivo relevance is uncertain. In probing transgenically labeled $\mathrm{PVH}^{\mathrm{MC} 4 \mathrm{R}}$ neurons in ex vivo slice preparations, a recent study revealed that a-MSH agonism, and subsequent neuron excitation, is mediated by the closure of the inwardly rectifying potassium channel Kir7.1, in a G-protein-, $\beta$-arrestin- and MAPK-independent manner ${ }^{111}$. However, this mechanism is cell-type specific, as the inhibitory action of $\alpha-M S H$ at $\mathrm{DMV}^{\mathrm{MC}} 4 \mathrm{R}$ neurons is contingent on $\mathrm{G}_{\mathrm{s}}$-mediated activation of an ATP-dependent potassium channel ${ }^{82}$. The relevance of these mechanisms to MC4R- regulated physiology remains to be determined, but genetic ablation of the Gsa (Gnas) coding region in mice, while not specific to MC4R, leads to profound syndromic obesity that is associated with reduced energy expenditure and sympathetic outflow, independent of hyperphagia ${ }^{112}$. Targeted deletion from Sim1 neurons promotes only mild obesity with no influence on feeding behavior ${ }^{113}$. These observations may suggest 
that MC4R coupling to $\mathrm{Ga}_{\mathrm{s}}$ in the $\mathrm{PVH}$ is not a functional requirement for the regulation of feeding behavior, potentially identifying a role for $\mathrm{Ga}_{\mathrm{q}}$ or G-protein-independent Kir7.1 signaling. Together these data indicate that the MC4R is likely to exhibit promiscuous coupling to multiple intracellular mediators in a physiology-specific context.

a-MSH signaling is potentiated by the actions of a conserved family of melanocortin receptor accessory proteins (MRAPs). The murine ${ }^{114}$ and teleost ${ }^{115}$ isoforms of MRAP2 sensitize the MC4R to a-MSH binding and augment signal transduction. In mice, the global or Sim1- specific deletion of the sole MRAP2 paralog results in late-onset obesity that is, paradoxically, not defined by hyperphagia or reduced energy expenditure (nor reduced anorectic sensitivity to MTII) ${ }^{114}$.

The melanocortin system is unique in possessing a second, counteracting ligand in the form of $\mathrm{AgRP}$. Initial pharmacological observations of $\mathrm{AgRP}$ function led to its characterization as an MC4R antagonist, serving to block a-MSH agonism ${ }^{116-118}$. AgRP has also been identified as an inverse agonist, operating independently of a-MSH to promote G-protein uncoupling at constitutively active MC4Rs ${ }^{119-122}$. However, the physiological significance of constitutive MC4R activity in vivo is unclear ${ }^{123}$. Most recently AgRP has been identified as a biased agonist, directly promoting membrane hyperpolarization independently of constitutive activity or agonist presence. This mechanism has been observed in both a Gprotein-dependent and G-protein-independent manner. In a heterologous cell system, AgRP binding selectively recruits $\mathrm{G}_{\mathrm{i} / \mathrm{o}}$, leading to reduced cAMP accumulation ${ }^{124}$, while in ex vivo $\mathrm{PVH}^{\mathrm{MC} 4 \mathrm{R}}$ neurons, AgRP drives G-protein-independent activation of Kir7.1 and subsequent hyperpolarization ${ }^{111}$. Little is yet known of the physiological significance of the MC4RKir7.1 interaction, but future genetic studies are likely to provide invaluable insights.

\section{MC4R pharmacotherapy}

Driven by the ever more pervasive issue of human obesity, much effort has been directed toward unraveling the neural circuits that coordinate the regulation of energy homeostasis and body weight. In fulfilling a highly conserved physiological function, the central melanocortin system sits at the intersection of obesity pathology and treatment. Nullizygous mutations in human $P O M C^{21}$ and $M C 4 R^{19,20,52}$ genes engender pleiotropic obesity syndromes that are consistent with their epistatic cofunctionality. Furthermore, POMC 25,126 and $M C 4 R^{52,127}$ haploinsufficiency predisposes carriers to obesity, albeit with varying penetrance that speaks to the importance of environmental factors and genetic modifiers. Indeed, $M C 4 R$ mutations represent the most prevalent form of monogenic obesity (0.5-6\% of obese individuals $)^{52}$, and $M C 4 R$ variations are highly correlated with fat mass ${ }^{128}$. However, contrasting this pathological association is the potential of the MC4R as a pharmacotherapeutic target for obesity ${ }^{129,130}$. Consistent with rodent studies, pharmacological compounds that augment MC4R signaling promote appetite suppression and weight loss in humans ${ }^{130}$. Unfortunately, these drugs influence other MC4R-regulated processes, such as cardiovascular tone, sexual function and pandiculation, limiting their clinical application ${ }^{129}$. At present only one MC4R compound, setmelanotide (RM-493; Rhythm Pharmaceuticals), is undergoing clinical trials, and only for use in the rare obesity conditions Prader-Willi syndrome and POMC deficiency. Setmelanotide reduces food intake 
and increase energy expenditure in several preclinical models ${ }^{131,132}$. In obese rhesus macaques ${ }^{132}$ and a small cohort of obese humans ${ }^{133}$, this drug had no adverse effects on blood pressure; however, the latter study reported sexual side effects ${ }^{133}$. Alternative strategies such as positive allosteric modulators (PAMs), which augment MC4R signaling upon orthosteric binding of a-MSH, and molecular chaperones, which increase cell surface availability of MC4Rs, are being investigated as a means of enhancing the efficacy of endogenous a-MSH to offer more physiologically relevant temporal specificity ${ }^{129}$.

Basic science efforts to experimentally identify the relevant neuronal populations that underlie the various physiological functions of the MC4R will be critical for the development of new obesity-specific compounds. Such studies will afford insight into the involvement of neuroanatomically discrete MC4R populations and potentially facilitate the identification of differentially expressed targets amenable to pharmacological manipulation. For instance, $\mathrm{PVH}^{\mathrm{MC} 4 \mathrm{R}}$ neurons are the preponderant agent of melanocortinergic appetite control and thus a foremost target for weight-loss therapies. While explicit pharmacological manipulation of these MC4Rs is as yet impossible and confounded by drug action at MC4R populations governing autonomic outflow, $\mathrm{PVH}^{\mathrm{MC} 4 \mathrm{R}}$ neurons express other potential targets not expressed in preautonomic MC4R neurons. Transcriptomic profiling will be vital for contrasting neuroanatomical populations of MC4R-expressing neurons and identifying physiology-specific targets. In addition, evidence of promiscuous MC4R intracellular coupling (see above) may also suggest that these receptors employ functionally exclusive signaling cascades. In vivo interrogation of these mechanisms may afford understanding of the signal transduction pathways that define the function of satiety-promoting MC4Rs.

\section{Conclusions and future directions}

The central melanocortin systems regulates body weight and overall metabolic fitness in a manner defined by its need-based orchestration of physiology and behavior. The initiation of these processes is contingent on the interoceptive function of counter-acting $\mathrm{ARC}^{\mathrm{AgRP}}$ and $A R C^{\mathrm{POMC}}$ neurons that represent a cellular interface between afferent indicators of physiological state and neural circuits governing response enactment. The capacity of the melanocortin system to subserve both catabolic and anabolic modalities of energy balance is determined by their antagonistic engagement of second-order MC4R-expressing neurons. While additional, non-MC4R mechanisms and populations contribute to aspects of $\mathrm{ARC}^{\mathrm{AgRP}}$ and $\mathrm{ARC}^{\mathrm{POMC}}$ functionality ${ }^{35}$, the phenotypic similitude arising from the experimental manipulations of these first- and second-order populations strongly supports MC4R expressing neurons as important mediators of melanocortinergic energy balance.

Conditional genetic manipulations of $M c 4 r$ expression reveal a functional divergence in the melanocortinergic circuitry, such that the regulation of specific physiologies or behaviors proceeds via neuroanatomically discrete populations of MC4R neurons (Fig. 3). Indeed, although many MC4R populations remain unexplored, experimental interrogation of those in the PVH (feeding behavior), DMV (insulin release) and IML (energy expenditure and glucose metabolism) has demonstrated their synergistic but non-overlapping functions. The rationalization of these phenotypes in the context of the upstream melanocortinergic circuitry has subsequently been facilitated by the application of modern neuroscience 
technologies. Thus, explicit genetic access to MC4R neurons in combination with these techniques affords understanding of both the up- and downstream circuitry that defines physiological function. In this regard, further deconvolution of the LPBN circuitry underlying the satiety effect of $\mathrm{PVH}^{\mathrm{MC} 4 \mathrm{R}}$ neurons is critical to understanding the means by which real-time fluctuations in energy state are translated into volitional behavior. The complex anatomical substructure, neurochemical composition and viscerotopic arrangement of the LPBN suggests that there is likely to be a functionally explicit population of neurons that integrates labeled lines of satiety-related homeostatic and visceral information and informs decision-making processes via its ascending projections, potentially to limbic (central nucleus of the amygdala, lateral hypothalamus, bed nucleus of the stria terminalis and corticothalamic structures (paraventricular nucleus of the thalamus and insular cortex). Furthermore, this homeostatic system is likely to be influenced by neural inputs that convey context- specific information to modulate functional output in accordance with the broader state of the animal and its environment. Expansion of this aspect of the melanocortinergic circuitry will have important implications for how homeostatic processes - in particular, feeding behavior - can be influenced by factors such as stress, reward and circadian rhythmicity, and provide insight into the complexity of human energy balance.

The rising prevalence of clinical obesity, due primarily to caloric overconsumption, has highlighted the need for more efficacious pharmacotherapies. The ability of MC4R compounds to promote weight loss has long been held as evidence of therapeutic potential, yet the multiplicity of physiologies regulated by this receptor has subverted the generation of a safe and effective drug. To this end, further basic science endeavor in deconvolving MC4R biology - in particular, with regard to the neurons that express these receptors, their circuitry and intracellular cascades that define their function-is critical for streamlining pharmaceutical efforts to specifically target the bodyweight-regulating MC4R neurons.

\section{Acknowledgments}

This work was supported by a University of Edinburgh Chancellor's Fellowship (A.S.G.) and US National Institutes of Health grants to B.B.L. (R01 DK096010, R01 DK089044, R01 DK071051, R01 DK075632, R37 DK053477, BNORC Transgenic Core P30 DK046200, BADERC Transgenic Core P30 DK057521) and to M.J.K. (Intramural Research Program, NIDDK; DK075087, DK075090).

\section{References}

1. Guh DP, et al. The incidence of co-morbidities related to obesity and overweight: a systematic review and meta-analysis. BMC Public Health. 2009; 9:88. [PubMed: 19320986]

2. Olshansky SJ, et al. A potential decline in life expectancy in the United States in the 21 st century. N Engl J Med. 2005; 352:1138-1145. [PubMed: 15784668]

3. Gautron L, Elmquist JK, Williams KW. Neural control of energy balance: translating circuits to therapies. Cell. 2015; 161:133-145. [PubMed: 25815991]

4. Garfield AS, Lam DD, Marston OJ, Przydzial MJ, Heisler LK. Role of central melanocortin pathways in energy homeostasis. Trends Endocrinol Metab. 2009; 20:203-215. [PubMed: 19541496]

5. Cone RD. Anatomy and regulation of the central melanocortin system. Nat Neurosci. 2005; 8:571578. [PubMed: 15856065]

6. Liu T, et al. Fasting activation of AgRP neurons requires NMDA receptors and involves spinogenesis and increased excitatory tone. Neuron. 2012; 73:511-522. [PubMed: 22325203] 
7. Yang Y, Atasoy D, Su HH, Sternson SM. Hunger states switch a flip-flop memory circuit via a synaptic AMPK-dependent positive feedback loop. Cell. 2011; 146:992-1003. [PubMed: 21925320]

8. Aponte Y, Atasoy D, Sternson SM. AGRP neurons are sufficient to orchestrate feeding behavior rapidly and without training. Nat Neurosci. 2011; 14:351-355. [PubMed: 21209617]

9. Atasoy D, Betley JN, Su HH, Sternson SM. Deconstruction of a neural circuit for hunger. Nature. 2012; 488:172-177. [PubMed: 22801496]

10. Krashes MJ, et al. Rapid, reversible activation of AgRP neurons drives feeding behavior in mice. $\mathrm{J}$ Clin Invest. 2011; 121:1424-1428. [PubMed: 21364278]

11. Zhan C, et al. Acute and long-term suppression of feeding behavior by POMC neurons in the brainstem and hypothalamus, respectively. J Neurosci. 2013; 33:3624-3632. [PubMed: 23426689]

12. Dodd GT, et al. Leptin and insulin act on POMC neurons to promote the browning of white fat. Cell. 2015; 160:88-104. [PubMed: 25594176]

13. Mandelblat-Cerf Y, et al. Arcuate hypothalamic AgRP and putative POMC neurons show opposite changes in spiking across multiple timescales. Elife. 2015; 4:e07122.

14. Cone RD. Studies on the physiological functions of the melanocortin system. Endocr Rev. 2006; 27:736-749. [PubMed: 17077189]

15. Girardet C, Butler AA. Neural melanocortin receptors in obesity and related metabolic disorders. Biochim Biophys Acta. 2014; 1842:482-494. [PubMed: 23680515]

16. Huszar D, et al. Targeted disruption of the melanocortin- 4 receptor results in obesity in mice. Cell. 1997; 88:131-141. [PubMed: 9019399]

17. Yaswen L, Diehl N, Brennan MB, Hochgeschwender U. Obesity in the mouse model of proopiomelanocortin deficiency responds to peripheral melanocortin. Nat Med. 1999; 5:1066-1070. [PubMed: 10470087]

18. Challis BG, et al. Mice lacking pro-opiomelanocortin are sensitive to high-fat feeding but respond normally to the acute anorectic effects of peptide-YY(3-36). Proc Natl Acad Sci USA. 2004; 101:4695-4700. [PubMed: 15070780]

19. Yeo GS, et al. A frameshift mutation in MC4R associated with dominantly inherited human obesity. Nat Genet. 1998; 20:111-112. [PubMed: 9771698]

20. Vaisse C, Clement K, Guy-Grand B, Froguel P. A frameshift mutation in human MC4R is associated with a dominant form of obesity. Nat Genet. 1998; 20:113-114. [PubMed: 9771699]

21. Krude H, et al. Severe early-onset obesity, adrenal insufficiency and red hair pigmentation caused by POMC mutations in humans. Nat Genet. 1998; 19:155-157. [PubMed: 9620771]

22. Qian S, et al. Neither agouti-related protein nor neuropeptide $Y$ is critically required for the regulation of energy homeostasis in mice. Mol Cell Biol. 2002; 22:5027-5035. [PubMed: 12077332]

23. Luquet S, Perez FA, Hnasko TS, Palmiter RD. NPY/AgRP neurons are essential for feeding in adult mice but can be ablated in neonates. Science. 2005; 310:683-685. [PubMed: 16254186]

24. Bewick GA, et al. Post-embryonic ablation of AgRP neurons in mice leads to a lean, hypophagic phenotype. FASEB J. 2005; 19:1680-1682. [PubMed: 16099943]

25. Gropp E, et al. Agouti-related peptide-expressing neurons are mandatory for feeding. Nat Neurosci. 2005; 8:1289-1291. [PubMed: 16158063]

26. Aston-Jones G, Deisseroth K. Recent advances in optogenetics and pharmacogenetics. Brain Res. 2013; 1511:1-5. [PubMed: 23422677]

27. Vardy E, et al. A new DREADD facilitates the multiplexed chemogenetic interrogation of behavior. Neuron. 2015; 86:936-946. [PubMed: 25937170]

28. Betley JN, Cao ZF, Ritola KD, Sternson SM. Parallel, redundant circuit organization for homeostatic control of feeding behavior. Cell. 2013; 155:1337-1350. [PubMed: 24315102]

29. Dietrich MO, Zimmer MR, Bober J, Horvath TL. Hypothalamic Agrp neurons drive stereotypic behaviors beyond feeding. Cell. 2015; 160:1222-1232. [PubMed: 25748653]

30. Cowley MA, et al. Leptin activates anorexigenic POMC neurons through a neural network in the arcuate nucleus. Nature. 2001; 411:480-484. [PubMed: 11373681] 
31. Bagnol D, et al. Anatomy of an endogenous antagonist: relationship between Agouti-related protein and proopiomelanocortin in brain. J Neurosci. 1999; 19:RC26. [PubMed: 10479719]

32. Wang D, et al. Whole-brain mapping of the direct inputs and axonal projections of POMC and AgRP neurons. Front Neuroanat. 2015; 9:40. [PubMed: 25870542]

33. Mountjoy KG, Mortrud MT, Low MJ, Simerly RB, Cone RD. Localization of the melanocortin-4 receptor (MC4-R) in neuroendocrine and autonomic control circuits in the brain. Mol Endocrinol. 1994; 8:1298-1308. [PubMed: 7854347]

34. Kishi T, et al. Expression of melanocortin 4 receptor mRNA in the central nervous system of the rat. J Comp Neurol. 2003; 457:213-235. [PubMed: 12541307]

35. Garfield AS, et al. A neural basis for melanocortin-4 receptor-regulated appetite. Nat Neurosci. 2015; 18:863-871. [PubMed: 25915476]

36. Krashes MJ, Shah BP, Koda S, Lowell BB. Rapid versus delayed stimulation of feeding by the endogenously released AgRP neuron mediators GABA, NPY, and AgRP. Cell Metab. 2013; 18:588-595. [PubMed: 24093681]

37. Molosh AI, et al. NPY Y1 receptors differentially modulate GABAA and NMDA receptors via divergent signal-transduction pathways to reduce excitability of amygdala neurons. Neuropsychopharmacology. 2013; 38:1352-1364. [PubMed: 23358240]

38. Semjonous NM, et al. Coordinated changes in energy intake and expenditure following hypothalamic administration of neuropeptides involved in energy balance. Int J Obes (Lond). 2009; 33:775-785. [PubMed: 19488048]

39. Wittmann G, Hrabovszky E, Lechan RM. Distinct glutamatergic and GABAergic subsets of hypothalamic pro-opiomelanocortin neurons revealed by in situ hybridization in male rats and mice. J Comp Neurol. 2013; 521:3287-3302. [PubMed: 23640796]

40. Jarvie BC, Hentges ST. Expression of GABAergic and glutamatergic phenotypic markers in hypothalamic proopiomelanocortin neurons. J Comp Neurol. 2012; 520:3863-3876. [PubMed: 22522889]

41. Hentges ST, Otero-Corchon V, Pennock RL, King CM, Low MJ. Proopiomelanocortin expression in both GABA and glutamate neurons. J Neurosci. 2009; 29:13684-13690. [PubMed: 19864580]

42. Vong L, et al. Leptin action on GABAergic neurons prevents obesity and reduces inhibitory tone to POMC neurons. Neuron. 2011; 71:142-154. [PubMed: 21745644]

43. Atasoy D, et al. A genetically specified connectomics approach applied to long-range feeding regulatory circuits. Nat Neurosci. 2014; 17:1830-1839. [PubMed: 25362474]

44. Petreanu L, Huber D, Sobczyk A, Svoboda K. Channelrhodopsin-2-assisted circuit mapping of long-range callosal projections. Nat Neurosci. 2007; 10:663-668. [PubMed: 17435752]

45. Lim BK, Huang KW, Grueter BA, Rothwell PE, Malenka RC. Anhedonia requires MC4Rmediated synaptic adaptations in nucleus accumbens. Nature. 2012; 487:183-189. [PubMed: 22785313]

46. Shen Y, Fu WY, Cheng EY, Fu AK, Ip NY. Melanocortin-4 receptor regulates hippocampal synaptic plasticity through a protein kinase A-dependent mechanism. J Neurosci. 2013; 33:464472. [PubMed: 23303927]

47. Butler AA, et al. Melanocortin-4 receptor is required for acute homeostatic responses to increased dietary fat. Nat Neurosci. 2001; 4:605-611. [PubMed: 11369941]

48. Ste Marie L, Miura GI, Marsh DJ, Yagaloff K, Palmiter RD. A metabolic defect promotes obesity in mice lacking melanocortin-4 receptors. Proc Natl Acad Sci USA. 2000; 97:12339-12344. [PubMed: 11027312]

49. Cui H, Lutter M. The expression of MC4Rs in D1R neurons regulates food intake and locomotor sensitization to cocaine. Genes Brain Behav. 2013; 12:658-665. [PubMed: 23786641]

50. Vaughan C, Moore M, Haskell-Luevano C, Rowland NE. Food motivated behavior of melanocortin-4 receptor knockout mice under a progressive ratio schedule. Peptides. 2006; 27:2829-2835. [PubMed: 16930774]

51. Farooqi IS, et al. Dominant and recessive inheritance of morbid obesity associated with melanocortin 4 receptor deficiency. J Clin Invest. 2000; 106:271-279. [PubMed: 10903343]

52. Farooqi IS, et al. Clinical spectrum of obesity and mutations in the melanocortin 4 receptor gene. $\mathrm{N}$ Engl J Med. 2003; 348:1085-1095. [PubMed: 12646665] 
53. Balthasar N, et al. Divergence of melanocortin pathways in the control of food intake and energy expenditure. Cell. 2005; 123:493-505. [PubMed: 16269339]

54. Shah BP, et al. MC4R-expressing glutamatergic neurons in the paraventricular hypothalamus regulate feeding and are synaptically connected to the parabrachial nucleus. Proc Natl Acad Sci USA. 2014; 111:13193-13198. [PubMed: 25157144]

55. Panaro BL, et al. The melanocortin- 4 receptor is expressed in enteroendocrine $\mathrm{L}$ cells and regulates the release of peptide YY and glucagon-like peptide 1 in vivo. Cell Metab. 2014; 20:1018-1029. [PubMed: 25453189]

56. Hatoum IJ, et al. Melanocortin-4 receptor signaling is required for weight loss after gastric bypass surgery. J Clin Endocrinol Metab. 2012; 97:E1023-E1031. [PubMed: 22492873]

57. Mirshahi UL, et al. The MC4R(I251L) allele is associated with better metabolic status and more weight loss after gastric bypass surgery. J Clin Endocrinol Metab. 2011; 96:E2088-E2096. [PubMed: 21976721]

58. Thiele TE, et al. Central infusion of melanocortin agonist MTII in rats: assessment of c-Fos expression and taste aversion. Am J Physiol. 1998; 274:R248-R254. [PubMed: 9458925]

59. Millington GW, Tung YC, Hewson AK, O'Rahilly S, Dickson SL. Differential effects of $\alpha-$, $\beta$ - and $\gamma_{2}$-melanocyte-stimulating hormones on hypothalamic neuronal activation and feeding in the fasted rat. Neuroscience. 2001; 108:437-445. [PubMed: 11738258]

60. Sims JS, Lorden JF. Effect of paraventricular nucleus lesions on body weight, food intake and insulin levels. Behav Brain Res. 1986; 22:265-281. [PubMed: 3098259]

61. Kim MS, et al. Hypothalamic localization of the feeding effect of agouti-related peptide and alphamelanocyte-stimulating hormone. Diabetes. 2000; 49:177-182. [PubMed: 10868932]

62. Michaud JL, et al. Sim1 haploinsufficiency causes hyperphagia, obesity and reduction of the paraventricular nucleus of the hypothalamus. Hum Mol Genet. 2001; 10:1465-1473. [PubMed: 11448938]

63. Holder JL Jr, et al. Sim1 gene dosage modulates the homeostatic feeding response to increased dietary fat in mice. Am J Physiol Endocrinol Metab. 2004; 287:E105-E113. [PubMed: 14982752]

64. Tolson KP, et al. Inducible neuronal inactivation of Sim1 in adult mice causes hyperphagic obesity. Endocrinology. 2014; 155:2436-2444. [PubMed: 24773343]

65. Kublaoui BM, Holder JL Jr, Gemelli T, Zinn AR. Sim1 haploinsufficiency impairs melanocortinmediated anorexia and activation of paraventricular nucleus neurons. Mol Endocrinol. 2006; 20:2483-2492. [PubMed: 16728530]

66. Morgan DA, et al. Regulation of glucose tolerance and sympathetic activity by MC4R signaling in the lateral hypothalamus. Diabetes. 2015; 64:1976-1987. [PubMed: 25605803]

67. Xu Y, et al. Glutamate mediates the function of melanocortin receptor 4 on Sim1 neurons in body weight regulation. Cell Metab. 2013; 18:860-870. [PubMed: 24315371]

68. Cui H, et al. Melanocortin 4 receptor signaling in dopamine 1 receptor neurons is required for procedural memory learning. Physiol Behav. 2012; 106:201-210. [PubMed: 22342812]

69. Rossi J, et al. Melanocortin-4 receptors expressed by cholinergic neurons regulate energy balance and glucose homeostasis. Cell Metab. 2011; 13:195-204. [PubMed: 21284986]

70. Berglund ED, et al. Melanocortin 4 receptors in autonomic neurons regulate thermogenesis and glycemia. Nat Neurosci. 2014; 17:911-913. [PubMed: 24908101]

71. Monge-Roffarello B, et al. The medial preoptic nucleus as a site of the thermogenic and metabolic actions of melanotan II in male rats. Am J Physiol Regul Integr Comp Physiol. 2014; 307:R158R166. [PubMed: 24808495]

72. Voss-Andreae A, et al. Role of the central melanocortin circuitry in adaptive thermogenesis of brown adipose tissue. Endocrinology. 2007; 148:1550-1560. [PubMed: 17194736]

73. Vaughan $\mathrm{CH}$, Shrestha YB, Bartness TJ. Characterization of a novel melanocortin receptorcontaining node in the SNS outflow circuitry to brown adipose tissue involved in thermogenesis. Brain Res. 2011; 1411:17-27. [PubMed: 21802070]

74. Song CK, et al. Melanocortin-4 receptor mRNA expressed in sympathetic outflow neurons to brown adipose tissue: neuroanatomical and functional evidence. Am J Physiol Regul Integr Comp Physiol. 2008; 295:R417-R428. [PubMed: 18550869] 
75. Richard D, Picard F. Brown fat biology and thermogenesis. Front Biosci (Landmark Ed). 2011; 16:1233-1260. [PubMed: 21196229]

76. Turer AT, Hill JA, Elmquist JK, Scherer PE. Adipose tissue biology and cardiomyopathy: translational implications. Circ Res. 2012; 111:1565-1577. [PubMed: 23223931]

77. Harms M, Seale P. Brown and beige fat: development, function and therapeutic potential. Nat Med. 2013; 19:1252-1263. [PubMed: 24100998]

78. Song CK, Jackson RM, Harris RBS, Richard D, Bartness TJ. Melanocortin-4 receptor mRNA is expressed in sympathetic nervous system outflow neurons to white adipose tissue. Am J Physiol Regul Integr Comp Physiol. 2005; 289:R1467-R1476. [PubMed: 16221982]

79. Fan W, et al. The central melanocortin system can directly regulate serum insulin levels. Endocrinology. 2000; 141:3072-3079. [PubMed: 10965876]

80. Greenfield JR, et al. Modulation of blood pressure by central melanocortinergic pathways. N Engl J Med. 2009; 360:44-52. [PubMed: 19092146]

81. Sutton GM, et al. Diet-genotype interactions in the development of the obese, insulin-resistant phenotype of C57BL/6J mice lacking melanocortin-3 or -4 receptors. Endocrinology. 2006; 147:2183-2196. [PubMed: 16469808]

82. Sohn JW, et al. Melanocortin 4 receptors reciprocally regulate sympathetic and parasympathetic preganglionic neurons. Cell. 2013; 152:612-619. [PubMed: 23374353]

83. Kuo JJ, da Silva AA, Tallam LS, Hall JE. Role of adrenergic activity in pressor responses to chronic melanocortin receptor activation. Hypertension. 2004; 43:370-375. [PubMed: 14707160]

84. Kuo JJ, Silva AA, Hall JE. Hypothalamic melanocortin receptors and chronic regulation of arterial pressure and renal function. Hypertension. 2003; 41:768-774. [PubMed: 12623994]

85. Ni XP, Butler AA, Cone RD, Humphreys MH. Central receptors mediating the cardiovascular actions of melanocyte stimulating hormones. J Hypertens. 2006; 24:2239-2246. [PubMed: 17053546]

86. Tallam LS, Stec DE, Willis MA, da Silva AA, Hall JE. Melanocortin-4 receptor-deficient mice are not hypertensive or salt-sensitive despite obesity, hyperinsulinemia, and hyperleptinemia. Hypertension. 2005; 46:326-332. [PubMed: 16027245]

87. Greenfield JR. Melanocortin signalling and the regulation of blood pressure in human obesity. J Neuroendocrinol. 2011; 23:186-193. [PubMed: 21062377]

88. Li P, et al. Melanocortin 3/4 receptors in paraventricular nucleus modulate sympathetic outflow and blood pressure. Exp Physiol. 2013; 98:435-443. [PubMed: 22872662]

89. Skibicka KP, Grill HJ. Hypothalamic and hindbrain melanocortin receptors contribute to the feeding, thermogenic, and cardiovascular action of melanocortins. Endocrinology. 2009; 150:5351-5361. [PubMed: 19854868]

90. Li P, et al. Melanocortin 4 receptors in the paraventricular nucleus modulate the adipose afferent reflex in rat. PLoS One. 2013; 8:e80295. [PubMed: 24244673]

91. Albarado DC, et al. Impaired coordination of nutrient intake and substrate oxidation in melanocortin-4 receptor knockout mice. Endocrinology. 2004; 145:243-252. [PubMed: 14551222]

92. Nogueiras R, et al. The central melanocortin system directly controls peripheral lipid metabolism. J Clin Invest. 2007; 117:3475-3488. [PubMed: 17885689]

93. Perez-Tilve D, et al. Melanocortin signaling in the CNS directly regulates circulating cholesterol. Nat Neurosci. 2010; 13:877-882. [PubMed: 20526334]

94. Saper CB. The central autonomic nervous system: conscious visceral perception and autonomic pattern generation. Annu Rev Neurosci. 2002; 25:433-469. [PubMed: 12052916]

95. Nagai K, et al. Lesions in the lateral part of the dorsal parabrachial nucleus caused hyperphagia and obesity. J Clin Biochem Nutr. 1987; 3:102-112.

96. Becskei C, Grabler V, Edwards GL, Riediger T, Lutz TA. Lesion of the lateral parabrachial nucleus attenuates the anorectic effect of peripheral amylin and CCK. Brain Res. 2007; 1162:76-84. [PubMed: 17617389]

97. Flak JN, et al. Leptin-inhibited PBN neurons enhance responses to hypoglycemia in negative energy balance. Nat Neurosci. 2014; 17:1744-1750. [PubMed: 25383904] 
98. Garfield AS, et al. A parabrachial-hypothalamic cholecystokinin neurocircuit controls counterregulatory responses to hypoglycemia. Cell Metab. 2014; 20:1030-1037. [PubMed: 25470549]

99. Carter ME, Soden ME, Zweifel LS, Palmiter RD. Genetic identification of a neural circuit that suppresses appetite. Nature. 2013; 503:111-114. [PubMed: 24121436]

100. Carter ME, Han S, Palmiter RD. Parabrachial calcitonin gene-related peptide neurons mediate conditioned taste aversion. J Neurosci. 2015; 35:4582-4586. [PubMed: 25788675]

101. Betley JN, et al. Neurons for hunger and thirst transmit a negative-valence teaching signal. Nature. 2015; 521:180-185. [PubMed: 25915020]

102. Keys A. Human starvation and its consequences. J Am Diet Assoc. 1946; 22:582-587. [PubMed: 20991087]

103. Berridge KC. Motivation concepts in behavioral neuroscience. Physiol Behav. 2004; 81:179-209. [PubMed: 15159167]

104. Hull, CL. Principles of Behavior: An Introduction to Behavior Theory. D. Appleton-Century; New York and London: 1943.

105. Breit A, et al. Alternative $\mathrm{G}$ protein coupling and biased agonism: new insights into melanocortin-4 receptor signalling. Mol Cell Endocrinol. 2011; 331:232-240. [PubMed: 20674667]

106. Gantz I, et al. Molecular cloning, expression, and gene localization of a fourth melanocortin receptor. J Biol Chem. 1993; 268:15174-15179. [PubMed: 8392067]

107. Newman EA, et al. Activation of the melanocortin-4 receptor mobilizes intracellular free calcium in immortalized hypothalamic neurons. J Surg Res. 2006; 132:201-207. [PubMed: 16580690]

108. Chai B, et al. Melanocortin-4 receptor-mediated inhibition of apoptosis in immortalized hypothalamic neurons via mitogen-activated protein kinase. Peptides. 2006; 27:2846-2857. [PubMed: 16806584]

109. Daniels D, Patten CS, Roth JD, Yee DK, Fluharty SJ. Melanocortin receptor signaling through mitogen-activated protein kinase in vitro and in rat hypothalamus. Brain Res. 2003; 986:1-11. [PubMed: 12965224]

110. Vongs A, Lynn NM, Rosenblum CI. Activation of MAP kinase by MC4-R through PI3 kinase. Regul Pept. 2004; 120:113-118. [PubMed: 15177928]

111. Ghamari-Langroudi M, et al. G-protein-independent coupling of MC4R to Kir7.1 in hypothalamic neurons. Nature. 2015; 520:94-98. [PubMed: 25600267]

112. Chen $M$, et al. Central nervous system imprinting of the $G$ protein $G(s) a l p h a$ and its role in metabolic regulation. Cell Metab. 2009; 9:548-555. [PubMed: 19490909]

113. Chen M, et al. Gsa deficiency in the paraventricular nucleus of the hypothalamus partially contributes to obesity associated with Gsa mutations. Endocrinology. 2012; 153:4256-4265. [PubMed: 22733970]

114. Asai M, et al. Loss of function of the melanocortin 2 receptor accessory protein 2 is associated with mammalian obesity. Science. 2013; 341:275-278. [PubMed: 23869016]

115. Sebag JA, Zhang C, Hinkle PM, Bradshaw AM, Cone RD. Developmental control of the melanocortin-4 receptor by MRAP2 proteins in zebrafish. Science. 2013; 341:278-281. [PubMed: 23869017]

116. Ollmann MM, et al. Antagonism of central melanocortin receptors in vitro and in vivo by agoutirelated protein. Science. 1997; 278:135-138. [PubMed: 9311920]

117. Yang YK, et al. Characterization of Agouti-related protein binding to melanocortin receptors. Mol Endocrinol. 1999; 13:148-155. [PubMed: 9892020]

118. Corander MP, Rimmington D, Challis BG, O'Rahilly S, Coll AP. Loss of agouti-related peptide does not significantly impact the phenotype of murine POMC deficiency. Endocrinology. 2011; 152:1819-1828. [PubMed: 21363936]

119. Tolle V, Low MJ. In vivo evidence for inverse agonism of Agouti-related peptide in the central nervous system of proopiomelanocortin-deficient mice. Diabetes. 2008; 57:86-94. [PubMed: 17909095] 
120. Breit A, et al. The natural inverse agonist agouti-related protein induces arrestin-mediated endocytosis of melanocortin-3 and -4 receptors. J Biol Chem. 2006; 281:37447-37456. [PubMed: 17041250]

121. Haskell-Luevano C, Monck EK. Agouti-related protein functions as an inverse agonist at a constitutively active brain melanocortin-4 receptor. Regul Pept. 2001; 99:1-7. [PubMed: 11257308]

122. Nijenhuis WA, Oosterom J, Adan RA. AgRP(83-132) acts as an inverse agonist on the humanmelanocortin-4 receptor. Mol Endocrinol. 2001; 15:164-171. [PubMed: 11145747]

123. Coll AP. Are melanocortin receptors constitutively active in vivo? Eur J Pharmacol. 2013; 719:202-207. [PubMed: 23872416]

124. Büch TR, Heling D, Damm E, Gudermann T, Breit A. Pertussis toxin-sensitive signaling of melanocortin-4 receptors in hypothalamic GT1-7 cells defines agouti-related protein as a biased agonist. J Biol Chem. 2009; 284:26411-26420. [PubMed: 19648111]

125. Krude $\mathrm{H}$, et al. Obesity due to proopiomelanocortin deficiency: three new cases and treatment trials with thyroid hormone and ACTH4-10. J Clin Endocrinol Metab. 2003; 88:4633-4640. [PubMed: 14557433]

126. Farooqi IS, et al. Heterozygosity for a POMC-null mutation and increased obesity risk in humans. Diabetes. 2006; 55:2549-2553. [PubMed: 16936203]

127. Vaisse C, et al. Melanocortin-4 receptor mutations are a frequent and heterogeneous cause of morbid obesity. J Clin Invest. 2000; 106:253-262. [PubMed: 10903341]

128. Loos RJ, et al. Prostate, Lung, Colorectal, and Ovarian (PLCO) Cancer Screening Trial; KORA; Nurses' Health Study; Diabetes Genetics Initiative; SardiNIA Study; Wellcome Trust Case Control Consortium; FUSION. Common variants near MC4R are associated with fat mass, weight and risk of obesity. Nat Genet. 2008; 40:768-775. [PubMed: 18454148]

129. Lee EC, Carpino PA. Melanocortin-4 receptor modulators for the treatment of obesity: a patent analysis (2008-2014). Pharm Pat Anal. 2015; 4:95-107. [PubMed: 25853469]

130. Fani L, Bak S, Delhanty P, van Rossum EF, van den Akker EL. The melanocortin-4 receptor as target for obesity treatment: a systematic review of emerging pharmacological therapeutic options. Int J Obes (Lond). 2014; 38:163-169. [PubMed: 23774329]

131. Kumar KG, et al. Analysis of the therapeutic functions of novel melanocortin receptor agonists in MC3R- and MC4R-deficient C57BL/6J mice. Peptides. 2009; 30:1892-1900. [PubMed: 19646498]

132. Kievit $\mathrm{P}$, et al. Chronic treatment with a melanocortin-4 receptor agonist causes weight loss, reduces insulin resistance, and improves cardiovascular function in diet-induced obese rhesus macaques. Diabetes. 2013; 62:490-497. [PubMed: 23048186]

133. Chen KY, et al. RM-493, a melanocortin-4 receptor (MC4R) agonist, increases resting energy expenditure in obese individuals. J Clin Endocrinol Metab. 2015; 100:1639-1645. [PubMed: 25675384]

134. Weide K, et al. Hyperphagia, not hypometabolism, causes early onset obesity in melanocortin-4 receptor knockout mice. Physiol Genomics. 2003; 13:47-56. [PubMed: 12644632]

135. Zhang Y, et al. Targeted deletion of melanocortin receptor subtypes 3 and 4, but not CART, alters nutrient partitioning and compromises behavioral and metabolic responses to leptin. FASEB J. 2005; 19:1482-1491. [PubMed: 16126916]

136. Chen AS, et al. Role of the melanocortin-4 receptor in metabolic rate and food intake in mice. Transgenic Res. 2000; 9:145-154. [PubMed: 10951699]

137. Marsh DJ, et al. Response of melanocortin-4 receptor-deficient mice to anorectic and orexigenic peptides. Nat Genet. 1999; 21:119-122. [PubMed: 9916804]

138. Fan W, et al. Cholecystokinin-mediated suppression of feeding involves the brainstem melanocortin system. Nat Neurosci. 2004; 7:335-336. [PubMed: 15034587]

139. Tallam LS, da Silva AA, Hall JE. Melanocortin-4 receptor mediates chronic cardiovascular and metabolic actions of leptin. Hypertension. 2006; 48:58-64. [PubMed: 16754792]

140. Arble DM, et al. The melanocortin-4 receptor integrates circadian light cues and metabolism. Endocrinology. 2015; 156:1685-1691. [PubMed: 25730108] 


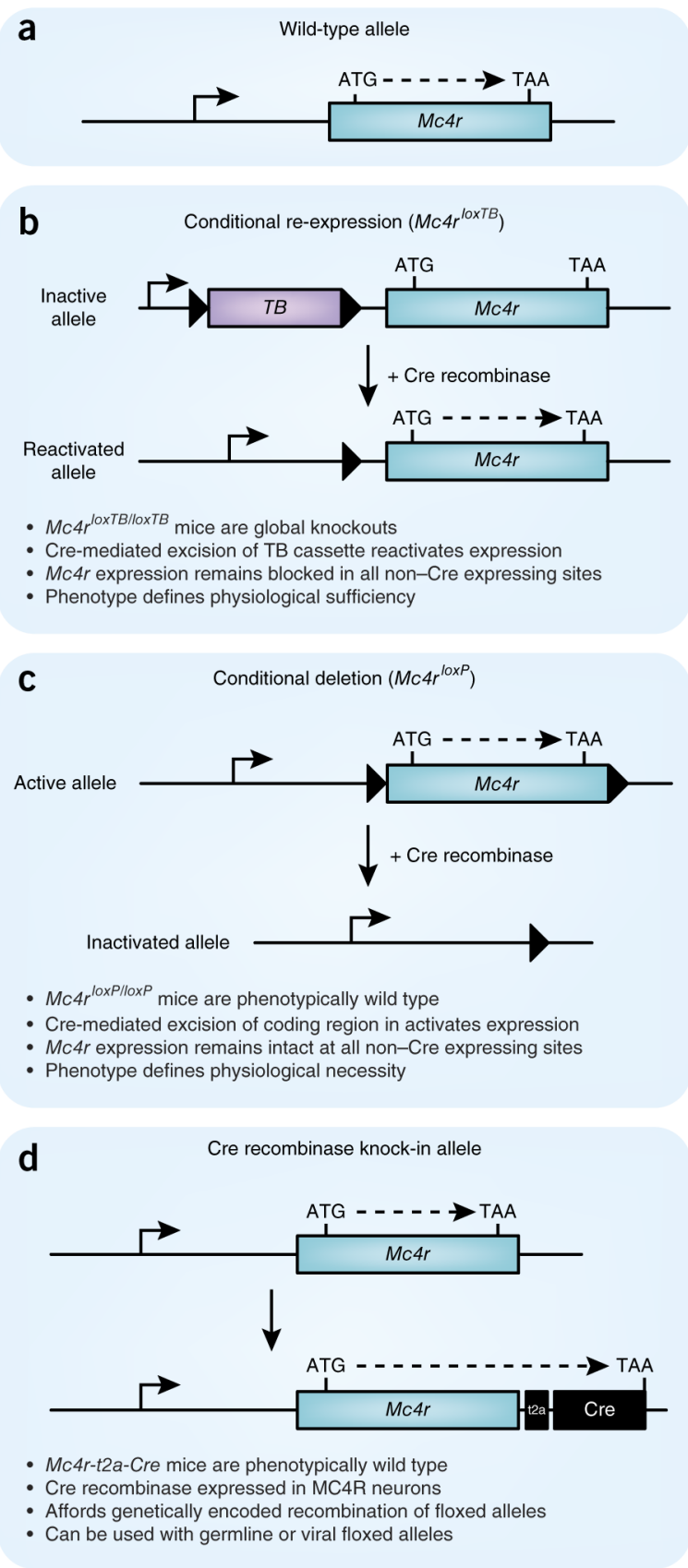

Figure 1.

Genetically modified Mc4r alleles. (a) Wild-type mouse $M c 4 r$ locus. (b,c) Conditional $M c 4 r$ alleles for the molecularly defined Cre-dependent re-expression (b) or deletion (c) of the $M c 4 r$ locus. (b) Conditional re-expression is achieved through the insertion between the transcriptional start site and the $M c 4 r$ coding region of a transcriptional blocking (TB) cassette flanked by loxP sites (triangles). Cre-dependent excision of the region between the lox $P$ sites removes the TB cassette and re-establishes $M c 4 r$ expression in Cre-expressing cells only. (c) Conditional deletion is achieved through the insertion of lox $P$ sites flanking the $M c 4 r$ coding region. Cre-dependent excision of the region between the lox $P$ sites deletes 
the coding region and inactivates the $M c 4 r$ locus in Cre-expressing cells only. (d) A knockin Mc4r-t2a-Cre driver line was generated by inserting a Cre recombinase cassette downstream of the $M c 4 r$ stop codon. 
a

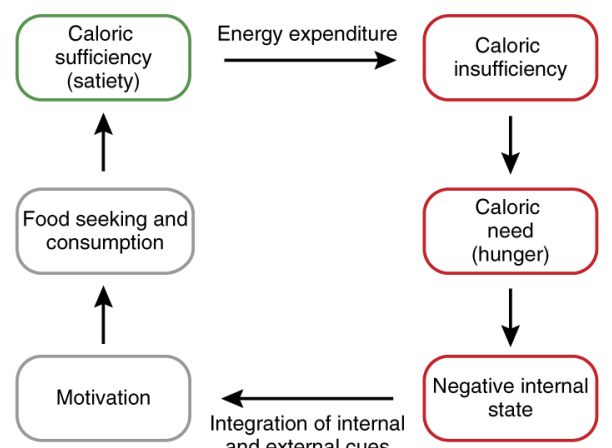

b

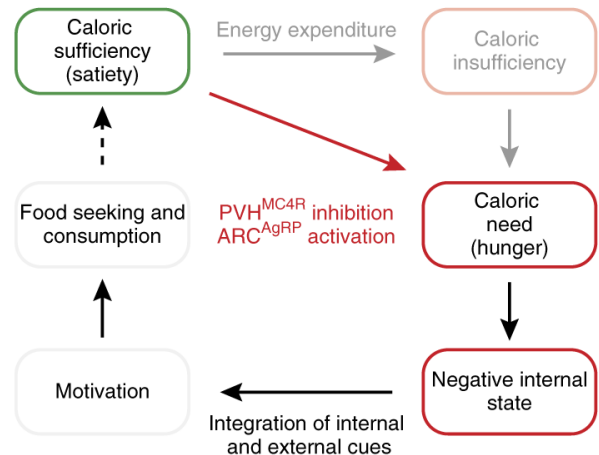

C

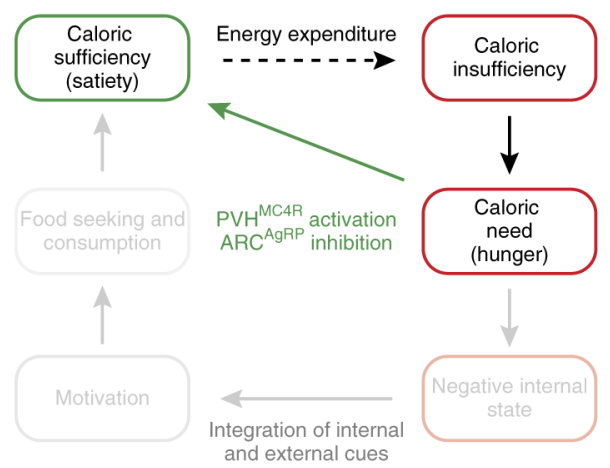

Figure 2.

Melanocortins and the motivational basis of feeding. (a) Caloric insufficiency arising from energy expenditure creates a negative state of tension that represents caloric need and is interoceptively recognized as hunger. This caloric need (hunger) carries a negative valence that provides the motivation to rectify the homeostatic disturbance, which must also take into consideration other internal and external cues before initiating goal-directed food seeking and consumption. Food detection and caloric ingestion relieves the aversive state of hunger, reducing the initiating motivation, and thus satiety carries a positive valence. Experimental manipulation of melanocortinergic neurons bypasses the drive-reduction circuit and artificially creates the states of hunger (b) and satiety (c). (b) A perceived state of caloric need is created upon the activation of $\mathrm{ARC}^{\mathrm{AgRP}}$ neurons or inhibition of $\mathrm{PVH} \mathrm{HC}^{\mathrm{MR}}$ neurons, artificially enhancing the motivation to consume food despite physiological caloric sufficiency. Consistent with the negative valence of hunger, the activation of ARCAgRP neurons is aversive. (c) A perceived state of caloric sufficiency is created upon the inhibition 
of $\mathrm{ARC}^{\mathrm{AgRP}}$ neurons or activation of $\mathrm{PVH}^{\mathrm{MC} 4 \mathrm{R}}$ neurons, artificially diminishing the motivation to consume food despite physiological caloric insufficiency. Consistent with the positive valence of satiety, the activation of $\mathrm{PVH}^{\mathrm{MC} 4 \mathrm{R}}(\rightarrow \mathrm{LPBN})$ neurons or inhibition of $\mathrm{ARC}^{\mathrm{AgRP}}$ neurons is appetitive. Red represents negative valence; green, positive valence. AgRP, agouti-related peptide; ARC, arcuate nucleus of the hypothalamus; MC4R, melanocortin-4 receptor; $\mathrm{PVH}$, paraventricular nucleus of the hypothalamus. 


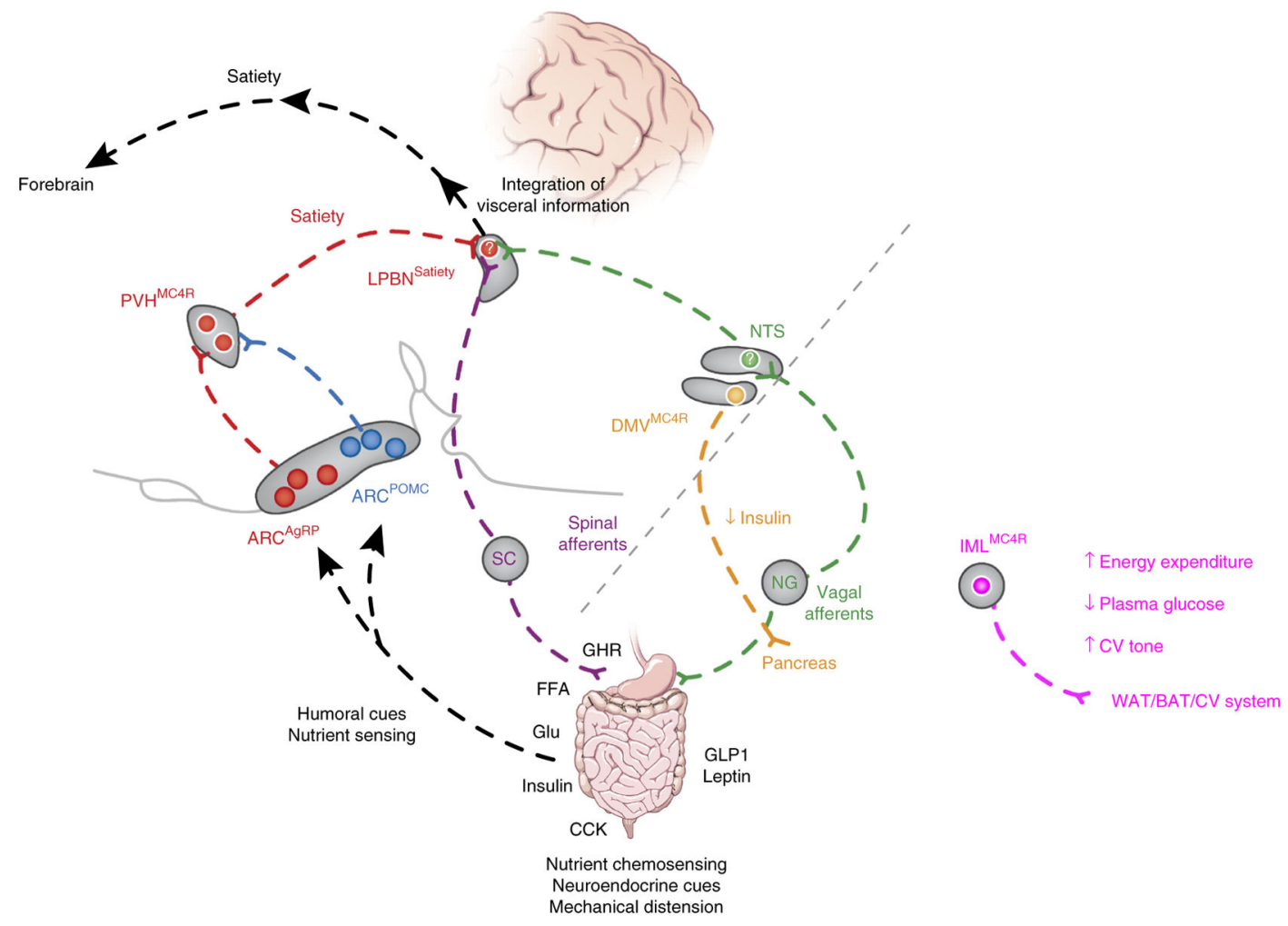

Figure 3.

Functional topography of Mc4r function. The conditional and AAV-mediated genetic manipulation of $M c 4 r$ expression has demonstrated a neuroanatomical dissociation of physiological function. $\mathrm{PVH}^{\mathrm{MC} 4 \mathrm{Rs}}$ are the predominant energy-intake-regulating population (and also govern body length) but do not influence energy expenditure. These neurons receive monosynaptic inhibitory input from $\mathrm{ARC}^{\mathrm{AgRP}}$ neurons and are necessary for the full $\mathrm{ARC}^{\mathrm{AgRP}} \rightarrow \mathrm{PVH}$ feeding phenotype. Real-time optogenetic interrogation identified the LPBN as the site of functional outflow for appetite-regulating $\mathrm{PVH}^{\mathrm{MC} 4 \mathrm{R}}$ neurons.

Furthermore, $\mathrm{PVH}^{\mathrm{MC} 4 \mathrm{R}} \rightarrow \mathrm{LPBN}$ satiety carries a positive valence, contrasting the negative valence associated with hunger-promoting ARC ${ }^{\mathrm{AgRP}}$ neurons. $\mathrm{PVH}^{\mathrm{MC} 4 \mathrm{R}} \rightarrow \mathrm{LPBN}$ neurons are depolarized by an MC4R agonist, suggesting that they are activated by upstream satietypromoting $\mathrm{ARC}^{\mathrm{POMC}}$ neurons, although this remains to be proven (blue line). A subtractive conditional genetic approach has implicated $M c 4 r$ expression on preganglionic parasympathetic neurons of the DMV in the tonic inhibition of pancreatic insulin release but not overall glycemic state or energy expenditure. MC4Rs on preganglionic sympathetic neurons of the IML govern overall sympathetic tone, leading to increased energy expenditure, hypertension and decreased glucose output. Red, ARC ${ }^{\mathrm{AgRP}} \rightarrow \mathrm{PVH}^{\mathrm{MC} 4 \mathrm{R}}$ satiety pathway; green, vagal afferents; purple, spinal afferents; yellow, parasympathetic nervous system; magenta, sympathetic nervous system; question mark, neuronal population of unknown identity. AgRP, agouti-regulated peptide; ARC, arcuate nucleus of the hypothalamus; CCK, cholecystokinin; CV, cardiovascular; DMV, dorsal motor nucleus of the vagus; FFA, free fatty acids; GHR, ghrelin; GLP1, glucagon-like peptide-1; IML, intermediolateral nucleus of the spinal cord; LPBN, lateral parabrachial nucleus; NG, 
nodose ganglion; NTS, nucleus of the solitary tract; MC4R, melanocortin-4 receptor; POMC, pro-opiomelanocortin; PVH, paraventricular nucleus of the hypothalamus; SC, spinal cord. 


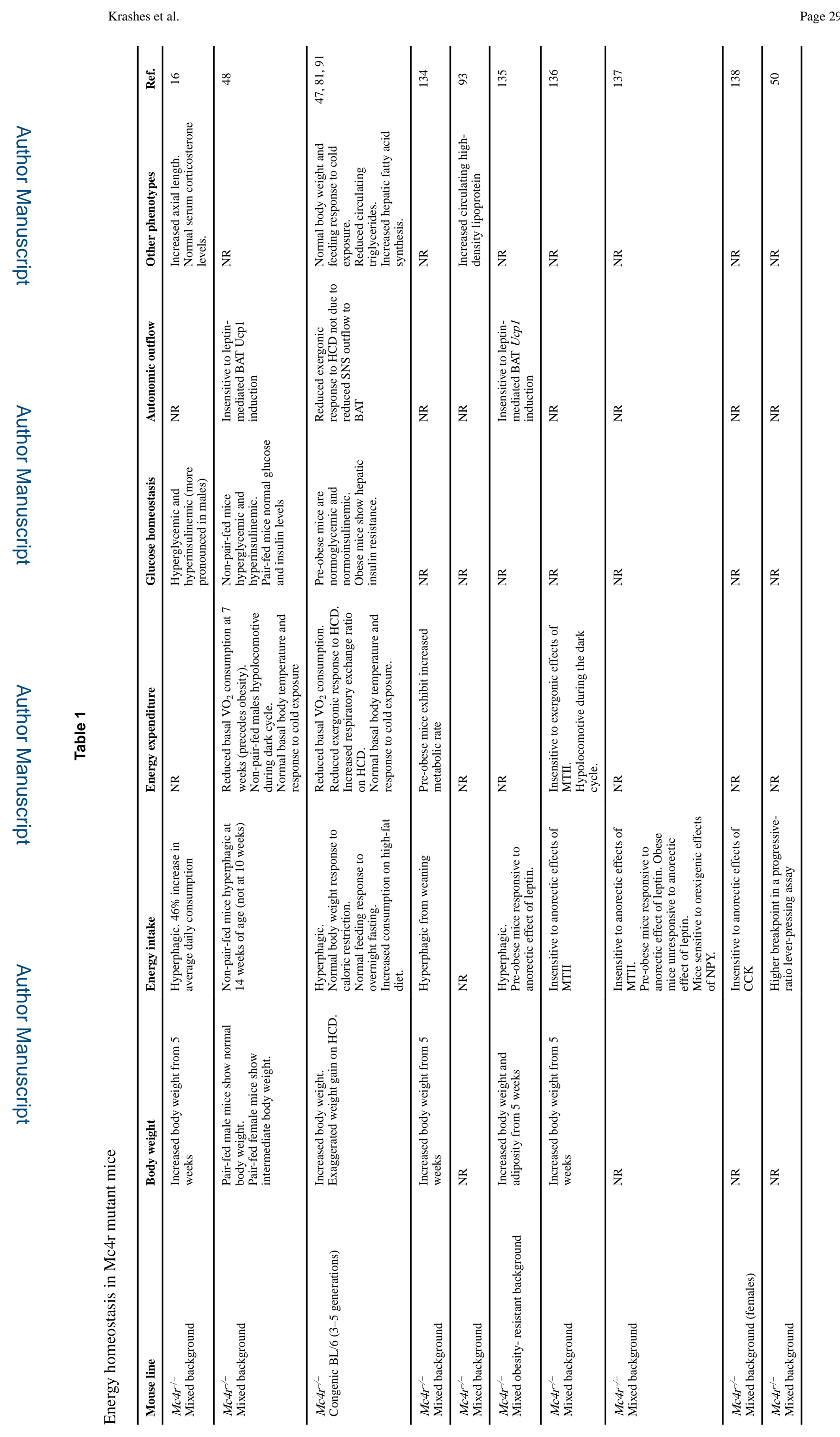

Nat Neurosci. Author manuscript; available in PMC 2017 January 19. 


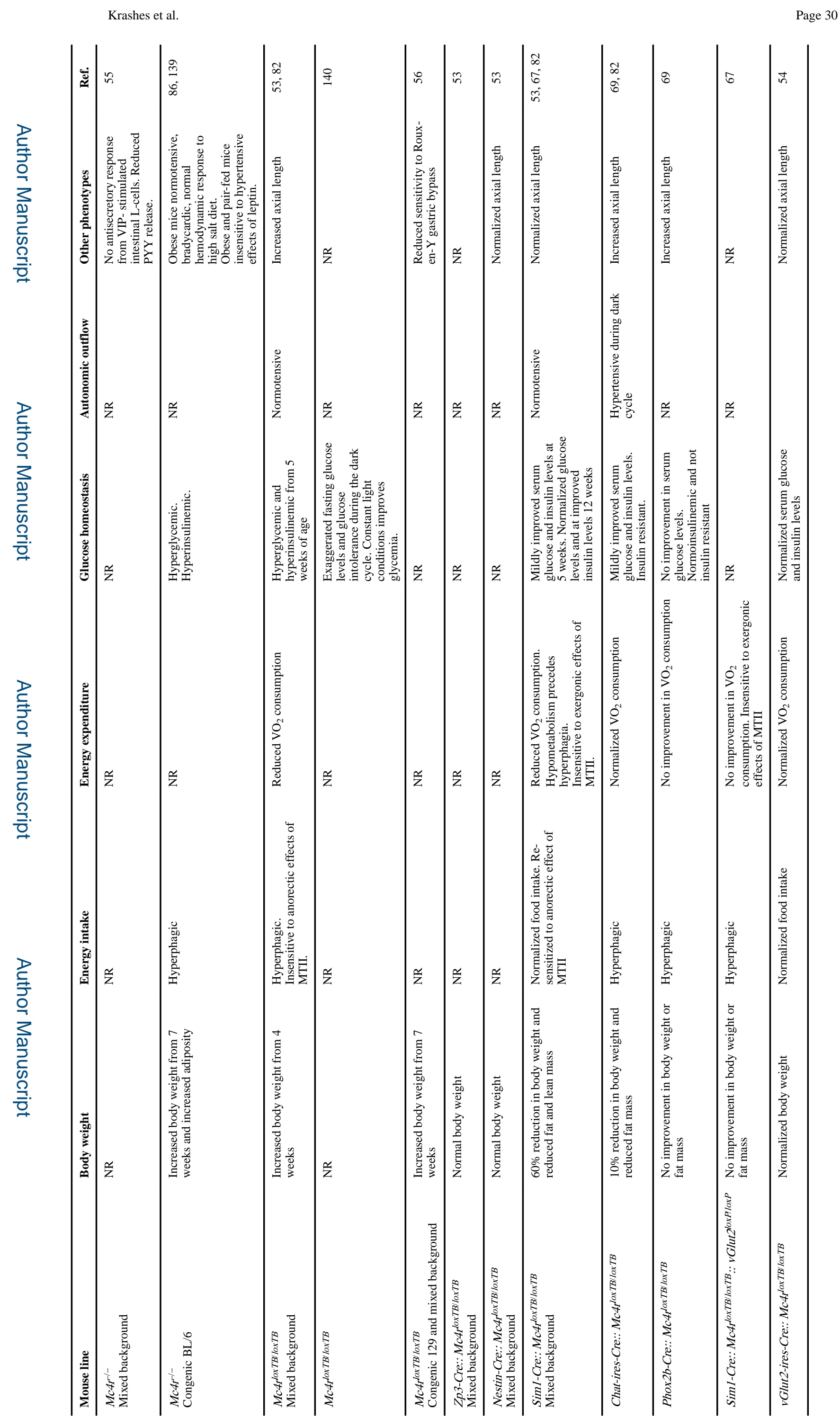





\section{Table 2}

\section{Cre driver lines used for $M c 4 r$ manipulation}

\begin{tabular}{llllc}
\hline Cre driver line & Type & Selectivity & $\begin{array}{l}\text { Main sites of neuroanatomical overlap with } \\
\text { Mc4r }\end{array}$ & Ref. \\
\hline Nestin (Nes) & Transgene & Pan-neuronal & All sites & 53 \\
vGlut2 (Slc17a6) & Knock-in & $\begin{array}{l}\text { Vesicular glutamate transporter (excitatory } \\
\text { neurons) }\end{array}$ & Most glutamatergic sites & 54 \\
vGat(Slc32a1) & Knock-in & Vesicular GABA transporter (inhibitory neurons) & Most GABAergic sites & 54 \\
Sim1 & Transgene & Single-minded 1 & PVH, MeA, NLOT, PH & 53 \\
Chat & Knock-in & Choline acetyltransferase (cholinergic neurons) & DMV, IML, LDTg, PPTg & 69 \\
Phox2b & Transgene & Paired-like homeobox 2b & DMV, NTS, NG & 69 \\
Drd1 & Transgene & Dopamine-1 receptor & NAc, PVH, & 49 \\
Oxt & Knock-in & Oxytocin & PVH & 54 \\
Avp & Knock-in & Arginine vasopressin & PVH & 54 \\
Pdyn & Knock-in & Pro-dynorphin & PVH, VMH, DMH, LH, DRN, LPBN & 54 \\
Crh & Knock-in & Corticotropin-releasing hormone & PVH & 54 \\
\hline
\end{tabular}

Cre driver lines used for manipulation of Mc4r conditional alleles. The genetic nature of each Cre line and its neuronal selectivity is provided. The listing of main sites of anatomical overlap defines only the most abundant sites of neuroanatomical coexistence between Mc4r and each Cre driver gene and not necessarily cellular coexpression. DMH, dorsomedial nucleus of the hypothalamus; DMV, dorsal motor nucleus of the vagus; DRN, dorsal raphe nucleus; IML, intermediolateral nucleus of the spinal cord; LDTg, laterodorsal tegmental nucleus; LH, lateral hypothalamus, LPBN, lateral parabrachial nucleus; MeA, medial amygdala; NAc, nucleus accumbens; NG, nodose ganglion; NLOT, nucleus of the lateral olfactory tract; NTS, nucleus of the solitary tract; PH, posterior hypothalamus; PPTg, pedunculopontine tegmental nucleus; PVH, paraventricular nucleus of the hypothalamus; VMH, ventromedial nucleus of the hypothalamus. 